\title{
Influence of large-scale circulation and interannual modes of climate variability on seasonal drought characteristics over Pakistan
}

Irfan Ullah

Nanjing University of Information Science and Technology

Xieyao Ma ( $\nabla$ xyma@nuist.edu.cn )

Nanjing University of Information Science and Technology https://orcid.org/0000-0002-3936-2020 Jun Yin

Nanjing University of Information Science and Technology

Farhan Saleem

Chinese Academy of Sciences

Sidra Syed

University of Peshawar

Abubaker Omer

Nanjing University of Information Science and Technology

Birhanu Asmerom Habtemicheal

Nanjing University of Information Science and Technology

\section{Research Article}

Keywords: Drought, Bayesian dynamic linear model, Climate Change, Large-scale drivers, Pakistan.

Posted Date: February 22nd, 2021

DOl: https://doi.org/10.21203/rs.3.rs-265535/v1

License: (c) (i) This work is licensed under a Creative Commons Attribution 4.0 International License.

Read Full License 


\section{Influence of large-scale circulation and interannual modes of climate variability on seasonal drought characteristics over Pakistan}

Irfan Ullah ${ }^{1}$, Xieyao $\mathrm{Ma}^{2, *}$, Jun Yin ${ }^{2}$, Farhan Saleem ${ }^{3,4}$, Sidra Syed ${ }^{5}$, Abubaker Omer ${ }^{2}$, Birhanu Asmerom Habtemicheal ${ }^{6,7}$

1 School of Atmospheric Sciences, Nanjing University of Information Science and Technology (NUIST), Nanjing 210044, China

${ }^{2}$ School of Hydrology and Water Resources, Nanjing University of Information Science and Technology (NUIST), Nanjing 210044, China

3 International Center for Climate and Environment Sciences, Institute of Atmospheric Physics, Chinese Academy of Sciences, Beijing 100049, China

${ }^{4}$ College of Earth and Planetary Sciences, University of Chinese Academy of Sciences

${ }^{5}$ Institute of Peace and Conflicts Studies, University of Peshawar, 25000 Peshawar, Pakistan

${ }^{6}$ Collaborative Innovation Centre on Forecast and Evaluation of Meteorological Disasters, Key Labortary of Aerosol-Cloud-Precipitation of China Meteorological administration, School of Atmospheric Physics, Nanjing University of Information Science and Technology (NUIST), Nanjing 210044, China

${ }^{7}$ Wollo University, Department of Physics P.O. Box 1145 Dessie, Ethopia

Corresponding author address: Professor, Dr. Xieyao Ma, School of Hydrology and Water Resources, Nanjing University of Information Science and Technology (NUIST), Nanjing 210044, China; Telephone: +86-18851778280

E-mail: xyma@nuist.edu.cn 


\section{Abstract}

The long-term drought monitoring and its assessment are of great importance for meteorological disaster risk management. The recurrent spells of heatwaves and droughts have severely affected the environmental conditions worldwide, including Pakistan. The present work sought to investigate the spatiotemporal changes in drought characteristics over Pakistan during Rabi and Kharif cropping seasons. The role of large-scale circulation and interannual mode of climate variability is further explored to identify the physical mechanisms associated with droughts in the region. Monthly precipitation and temperature data (1983-2019) from 53 meteorological stations were used to study drought characteristics, using the standardized precipitation evapotranspiration index (SPEI). The non-parametric Mann-Kendall (MK), Sen's Slope (SS), and Sequential Mann-Kendall (SQMK) tests were applied on the drought index to determine the statistical significance and magnitude of the historical trend. The state-of-the-art Bayesian Dynamic Linear (BDL) model was further used to analyze large scale climate drivers of droughts, analysis revealed an increase in drought severity mostly over arid to semi-arid regions for both cropping seasons. Temperature played a significant role in defining droughts over dry and hot seasons, while rainfall is influential over the western disturbances (WD) influenced region. The analysis of atmospheric circulation patterns revealed that large-scale changes in wind speed, air temperature, relative humidity and geopotential height anomalies are the likely drivers of droughts in the region. We found that Niño4, Sea Surface Temperature (SST), and multivariate El Niño-Southern Oscillation (ENSO4.0) Index are the most influential factors for seasonal droughts across Pakistan. Overall, the findings provide a better understanding of drought-prone areas in the region, and this information is of potential use for mitigating and managing drought risks.

Keywords Drought, Bayesian dynamic linear model, Climate Change, Large-scale drivers, Pakistan. 


\section{Introduction}

Drought is recognized as one of the most severe hydrometeorological disasters, caused by prolonged dry spells due to the below-average rainfall amounts(Dai 2013; Yang et al. 2020). Several studies have recently reported an increase in drought occurrence because of shifting climatic patterns (i.e., rainfall and temperature) (Duffy et al. 2015; Ahmed et al. 2018; HuiMean et al. 2018; Himayoun and Roshni 2019). The frequency and intensity of drought is projected to increase in many regions by the end of the $21^{\text {st }}$ century (Dai 2013). It is essential to study the climate-drought relationship for risk reduction and climate change adaptation (Ahmed et al. 2018). A recent study has reported the global warming-induced soil moisture deficit during summer and spring seasons in semi-arid regions, leading to greater drought risk vulnerability (Wu et al. 2018). The rising temperature patterns with below-average rainfall could decrease soil moisture contents over arid to semi-arid regions, making it more vulnerable to drought risks (Himayoun and Roshni 2019; Ain et al. 2020).

Recently, Pakistan has been severely impacted by extreme events such as heatwaves, floods, and droughts (Adnan et al. 2016; Ahmed et al. 2018; Ain et al. 2020). However, the country is situated in a predominantly arid region where the temperature is extremely high and precipitation is low (Haroon et al. 2016). The economy is highly dependent on agriculture, which plays a significant role in economic growth (Ashraf and Routray 2015). In winter and summer seasons, Pakistan receives enough amount of rainfall, while early spring season the moisture is transported from the Mediterranean and Caspian Sea developing western weather system (Ahmed et al. 2018; Anjum et al. 2018). Drought is a well-known natural hazard in Pakistan, which occurs at least every four out of ten years (Ahmed et al. 2018). The agriculture sector contributes about 25\% to Gross Domestic Product (GDP) and employs approximately 45\% of the total labor-workers (Ullah et al. 2017; Ain et al. 2020). 
Most of the country population lives in rural areas and depend on agriculture production as their primary income source.

Numerous studies have been conducted in Pakistan to identify the spatiotemporal characteristics of droughts on annual and seasonal timescales as well as long term trends in these characteristics (Ahmed et al. 2018; Hina and Saleem 2019; Adnan et al. 2020; Naz et al. 2020). A recent study has reported that the seasonal drought exhibits a cumulative trend in south-eastern Pakistan, while a declining trend is evident in the northwest coastal belt (Naz et al. 2020). Moreover, the drought events in Rabi and Kharif seasons have shown an upward trend in the south-eastern Pakistan, while a downward trend in the central region (Ahmed et al. 2018). The interannual variability of seasonal droughts over Pakistan is projected to increase in the near future, which may lead to adverse effects on the environment and society (Chatterjee et al. 2016; You et al. 2017). The studies mentioned above have provided detailed information about the spatiotemporal changes in annual and seasonal droughts characteristics over Pakistan, however, none of the studies have reported the large-scale climate drivers of the seasonal drought variability.

The El Niño Southern Oscillation (ENSO) is the primary mode of interannual variability in the tropical Pacific with significant impacts on global weather and climate via atmospheric circulations. Given this, efforts have been made to develop different forecasting methods to predict ENSO evolution several seasons in advance (Endris et al. 2019; Kang and Lee 2019). It is well documented in the literature that interannual rainfall variability over Pakistan is influenced by several dominant large-scale modes of climate variability (Ahmed et al. 2018; Sajjad and Ghaffar 2019), including ENSO new Version-4 (ENSO4.0) defined by the sea surface temperature (SST) anomalies in the central and eastern equatorial Pacific Ocean(McBride and Nicholls 1983), the Indian Ocean Dipole (IOD) defined by SST gradients in the west-eastern tropical Indian Ocean (Saji and Yamagata 2003), and the 
Southern Annular Mode (SAM), which refers to the atmospheric circulation in the mid to high latitudes of the southern hemisphere on inter-annual timescales (Marshall 2003).

On longer timescales, the temperature of Pakistan has been increasing due to anthropogenic climate change, yet there have been no significant changes in precipitation. For instance, the mean surface temperature has increased by $0.1^{\circ} \mathrm{C} /$ decade during $1960-2010$ over Pakistan (IPCC 2014; Khan et al. 2018). ENSOs is one of the dominant factors of climate variability in the tropical Indian Ocean, showing a possible influence on Pakistan's rainfall variability (Ain et al. 2020). In contrast, most of the tropical and semi-arid regions suffer from droughts during El Niño events. The phenomena of drought are widespread in the arid and semi-arid regions during La Niña (Bates et al. 2008; Ahmed et al. 2018). In addition, the SST based (Niño3.4-SST, and Niño4-SST) in the south-eastern Indian Ocean may also cause heavy rainfall (Ali et al. 2019). Most recently, Das et al. (2020), and Mishra (2020) found that Niño4-SSTs are the most influential factor in triggering heavy precipitation over the southeasterm Indian Ocean in near future. This is, in part, because the negative phase of IOD is associated with La Niña events showing a dipole pattern of SST with warming (dry) and cooling (wet) in the east-western Indian Ocean (Mishra et al. 2020, 2021; Ehsan et al. 2020). It is anticipated that the complex interactions between internal modes of variability and climate change has, and will continoue, to change Pakistan's drought characteristics in space and time .

Though the aforementioned studies have investigated the seasonal drought characteristics and its trend over Pakistan; however, several aspects of the seasonal droughts and its associated mechanisms are not sufficiently understood. The current study explores the underlying physical mechanisms of seasonal droughts and different modes of climate variability in the region (Pakistan) to fill these gaps. We used state-of-the-art Bayesian Dynamic Linear (BDL) model to study the influences of large-scale climate indices on 
seasonal droughts over Pakistan. The finding of the study would provide better understanding of the seasonal drought characteristics over Pakistan, essential for improving the drought risk reduction and management strategies. The rest of the paper is organized as follows: Section 2 provides the details about the study area while Section 3 presents datasets and methodologies. The results of the investigation are shown in Section 4. Section 5 elucidates discussions and conclusions based on significant outcomes.

\section{Study area}

Geographically, Pakistan $\left(23^{\circ}-37^{\circ} \mathrm{N}\right.$ and $\left.60^{\circ}-78^{\circ} \mathrm{E}\right)$ is located in central-south Asia, covering a total area of $881,913 \mathrm{~km}^{2}$ (Fig. 1). The country receives maximum rainfall in the summer season, accounting for more than $65 \%$ of the annual total precipitation (Waqas and Athar 2019). The mean annual maximum and minimum temperatures are 15 to $35^{\circ} \mathrm{C}$ and 0 to $20^{\circ} \mathrm{C}$ across the country. Pakistan has two main seasons: summer and winter monsoon; the summer monsoon precipitation spans four months from June to September, and winter precipitation extents over December to March. The westerly disturbance in the Mediterranean Sea caused by winter monsoon precipitation, while the monsoon winds mostly cause the summer precipitation originated from the Bay of Bengal (Ahmed et al. 2018; Khan et al. 2020). The Rabi (winter) and Kharif (summer) are the two distinct cropping seasons in the region. Kharif season starts in May and ends in October, and is characterized by soil moisture plentiful enough to support the rain-fed crops. The main Kharif season crops include rice, maize, sugarcane, and cotton. Similarly, the Rabi season fluctuates with respect to latitude and is mostly influenced by the monsoon departure. Furthermore, the Rabi season begins in November and ends in April and the Rabi season crops include peas, gram, wheat, and mustard (Miyan 2015; Adnan et al. 2020).

\section{Materials and Methods}




\subsection{In-situ observations}

The monthly rainfall and temperature datasets (1983-2019) of 53 meteorological stations were archived from the Pakistan Meteorological Department (PMD). A brief summary of the selected meteorological stations is presented in Table S1. The monthly values were summed up to make the seasonal and annual time series of temperature and precipitation datasets. The seasonal drought was categorized as follows: Kharif season (May to October) and Rabi season (November to April). Moreover, the seasonal mean precipitation and temperature were calculated by averaging the mean rainfall and temperature of the selected months. The standardized normalized homogeneity test (SNHT) is among the commonly used statistical technique for estimating the uniformity of climatic data records; therefore, the main purpose of SNHT and homogenization assessment is to find out the peaks and outliers in datasets attributed by non-climatic factors (Toreti et al. 2011; Akhtar and Athar 2019). During the climatic signal's preservation, only $(<2 \%)$ of the data was missing (a few stations) that do not substantially affect the outcomes of the study to a broader range.

\subsection{Reanalysis dataset}

Recently, the European Centre for Medium-Range Weather Forecasts (ECMWF) developed a global reanalysis dataset, namely ERA-5, which was used in the present study. ERA-5 is the 5th global atmospheric reanalysis product developed by ECMWF following FGGE, ERA-15, ERA-40, and ERA-Interim, with key strengths and advances over ERA-Interim. Large-scale treatment of precipitation and clouds, the inclusion of analytical variables for precipitating and snow, model boundary layer conditions, and radioactive data are among the key aspects of ERA-5 dataset (Hersbach et al. 2019). The output appeared to be better with these changes and improvements, representing the large-scale tropospheric circulations since 1979 (Olauson 
2018). In the present study, meridional wind speed, soil moisture, geopotential height 850 $\mathrm{hPa}$, total precipitation, $2 \mathrm{~m}$ relative humidity $850 \mathrm{hPa}$, and $2 \mathrm{~m}$ air temperature were used.

\subsection{Large scale indices}

Climate change is not the only factor affecting droughts severity in the region; therefore, interannual modes of climate variability, defined by common large-scale indices, are further investigated (Gao et al. 2017; Yang et al. 2019, 2020). These large-scale indices include oceanic SST fluctuation, atmospheric circulation, and air pressure fluctuation, etc. In recent decades, many studies have been conducted at regional and global scale associated with the ENSO4.0, IOD, and monsoon variability towards extreme climate events (i.e., floods and droughts) conditions in the monsoon region (Gao et al. 2017; Joshi and Kar 2018; Yang et al. 2020). However, in the region of Pakistan, the westernmost boundary of South Asian monsoon system is not explored in terms of precipitation and temperature variability. This study chooses seven indices as a potential driver, representing the large-scale mode of climate variability. Detailed information on each index is given in Table 1. The monthly data (19832019) for each index were archived from (https://psl.noaa.gov/data/climateindices/list/).

\subsection{Standardized precipitation evapotranspiration index (SPEI)}

The SPEI considers potential evapotranspiration (PET) in addition to precipitation for evaluating drought conditions (Vicente-Serrano et al. 2010), and therefore found to be more efficient in constructing the temporal variability of droughts with respect to climate change perspective (Himayoun and Roshni 2019; Adnan et al. 2020). Furthermore, in SPEI the collected monthly precipitation and PET differences at various timescales are fitted with a 3parameter probability distribution function (PDF). The best fitted PDF of those estimated parameters are used to calculate the SPEI values. The detailed information about SPEI is given by Vicente-Serrano et al. (2010). The state of drought is classified by SPEI values as: 
mild drought $($ SPEI $\leq-1.0)$, moderate drought $(-1.5<$ SPEI $\leq-1.0)$, severe drought $(-2.0<$ SPEI $\leq-1.5$ ), and extreme drought refer to (SPEI $\leq-2.0$ ), respectively. In this study, we used the 6-month SPEI values for seasonal analysis and 12-month SPEI values were adopted as the annual timescale.

\subsection{Trend descriptive statistics}

In current study, the rank-based non-parametric modified-MK (Kendall 1955), Sequential Mann-kendall (SQMK) (Sneyers 1990), and Sen's Slope (SS) estimator (Sen 1968) were applied to detect secular trends in auto-correlated SPEI data (Ahmed et al. 2018; Yang et al. 2020). The presence of autocorrelation in the data could affect the probability of trend detection. Hamed and Rao (1998) suggested that the trend estimator should be subtracted from the original time series to estimate the autocorrelation. After that, modified-MK test was employed to detect the significance of the monotonic trend in SPEI, temperature and precipitation (Ahmed et al. 2018; Yang and Zhang 2018; Yu et al. 2018). Moreover, the modified-MK test was further used for SPEI values and secular trends with $p$-value $<0.05$ were considered as statistically significant. Likewise, the SS estimator was applied to determine the slope of the trend in SPEI time series (Ain et al. 2020; Adnan et al. 2020). In addition, the SQMK test was used to perceive the abrupt changes in SPEI time series at seasonal and annual timescales over time (Himayoun and Roshni 2019). The aforesaid statistical approaches are briefly described in previous research studies (Ahmed et al. 2018; Himayoun and Roshni 2019; Yang et al. 2020). The mathematical equations of modified-MK test statistic $(\mathrm{S})$ is given below as:

$S=\sum_{k=1}^{n-1} \quad \sum_{i=k+1}^{n} \operatorname{Sgn}\left(X_{i}-X_{k}\right)$

where $\operatorname{Sgn}\left(X_{i}-X_{k}\right)$ is calculated from Eq. (2), 
$\operatorname{Sgn}\left(X_{i}-X_{k}\right)= \begin{cases}+1, & \text { if }\left(X_{i}-X_{k}\right)>0 \\ 0, & \text { if }\left(X_{i}-X_{k}\right)=0 \\ -1, & \text { if }\left(X_{i}-X_{k}\right)<0\end{cases}$

where $n$ shows the length of time series, $X_{i}$ and $X_{k}$ are the sequential data values at time observation $j$ and $k$, and $S g n$ denotes the symbolic function that accepts the values 1,0 , or -1 ; if $X_{i}>X_{k}, X_{i}=X_{k}$ or $X_{i}<X_{k}$, respectively.

$$
Z= \begin{cases}\frac{(S-1)}{\sqrt{\operatorname{Var}(S)},} & \text { if } S>0 \\ 0, & \text { if } S=0 \\ \frac{(S-1)}{\sqrt{\operatorname{Var}(S)},} & \text { if } S<0\end{cases}
$$

In Eq. 3, $\operatorname{Var}(S)$ is the variance of $S$ whereas, the computed standardized $(Z)$ values with variance " 1 " and average " 0 " follow normal distribution time series data, while it is applied to measure the significance of the trend(Bayer Altın and Barak 2017).

$Z_{i}=\Phi^{-1}\left(\frac{R_{i}}{n+1}\right)$

where, $n$ is the data points and $\Phi^{-1}$ indicate the inverse standard normal distribution, while the correlation matrix of the time series was calculated from the Hurst coefficient $(H)$ (Koutsoyiannis 2003). $R_{i}$ is the rank of equivalent normal variants of the de-trended series.

$C_{n}(H)=\left[\rho_{|j-i|}\right]$, for $i=1: n ; j=1: n$

$\rho_{l}=\frac{1}{2}\left(|l+1|^{2 H}-2|l|^{2 H}+|l-1|^{2 H}\right)$

In Eq. 5 and $6, i, j, k$ indicates the length of time series and $\rho_{l}$ show autocorrelation function of lag $l$ for a given $H$. The significance level of $H$ was defined by the mean and standard deviation of $H=0.5$. In addition, to remove bias in $V(S)^{H \prime}$ estimation we used bias correction factor. Where $B$ indicate the function of $H$, while calculating the significance of modified-MK we replace $V(S)$ with $V(S)^{H}$. 
$V(S)^{H^{\prime}}=\sum_{i<j} \sum_{k<l} \frac{2}{\pi} \sin ^{-1}\left(\frac{\rho|j-i|-\rho|i-l|-\rho|j-k|+\rho|i-k|}{\sqrt{(2-2 \rho|i-j|)(2-2 \rho|k-l|)}}\right)$

$V(S)^{H}=V(S)^{H \prime} \times B$

For SS estimation (Eq. 9), the changes in $Q$ time series are calculated as the median of $N$ slopes computed from two consecutive points of the series.

$Q=\left\{\begin{array}{cl}Q([(N+1) / 2]), & \text { if } n \text { is odd } \\ Q[N / 2]+Q[(N+2) / 2] / 2, & \text { if } n \text { is even }\end{array}\right.$

For linear regression (Eq. 10), $Y$ represents the precipitation and temperature trend; $X$ shows the input precipitation and temperature over time; while $a$ and $b$ are indicated the regression coefficients, and intercepts, accordingly.

$Y=a X+n$

The SQMK test is calculated through applying ranked values $\left(y_{i}\right)$ of the data time series such as $x_{1}, x_{2} \ldots \ldots x_{n}$ during analysis. The magnitude of the $y_{i}$ value, $(i=1,2 \ldots n)$ are calculated with $y_{j}$ as the value for $(j=1 \ldots i-1)$. However, for assessment, each case where $y_{i}$ values greater than $y_{j}$ are calculated and represented by $n_{i}$. A mathematical statistic $\left(t_{j}\right)$ can be defined as, (Ahmed et al. 2018; Chen et al. 2019) in Eq. (11).

$t_{j}=\sum_{1}^{j} n_{j}$

The calculation of test statistics $t_{i}$, has a mean as in Eq. (12),

$$
E(t)=\frac{[n(n-1)]}{4}
$$

For variance, the statistical test computed as in Eq. (13),

$$
\operatorname{Var}\left(t_{j}\right)=j(j-1)(2 j+5) / 72
$$

For mitigation and standardized variable of the sequential values, statistical test $U F(t)$ is computed for each of the test statistic variables $t_{j}$ as follow in Eq. (14). 
$U F(t)=\left[t_{j}-E(t)\right] / \sqrt{\operatorname{Var}}\left(t_{j}\right)$

In Eq. 14, the null hypothesis values will be accepted at the significant level, if $|U F(t)| \leq$ $U F(t)_{1-\alpha / 2}$, where $U F(t)_{1-\alpha / 2}$ of the critical value of standard normal distribution whose probability value exceeds $\alpha / 2$ and where $\alpha$ value set as 0.05 . Moreover, the decrease values of UF show as a negative trend in time series and vice versa (Zhong et al. 2018; Zhang et al. 2019).

\subsection{Bayesian dynamic linear model}

Bayesian dynamic linear (BDL) model was applied to calculate the time-varying impacts of large-scale climate dynamic on meteorological drought over Pakistan during 1983-2019. The BDL model has the capability to model the dynamic and time-varying association between potential climate drivers and drought. The model has higher accurateness than the traditional linear regression. With this potential, BDL-model has been widely employed to detect the time-varying features of time series in climate and hydrology research. For instance, Yang et al. (2020) applied BDL model to check the dynamic impacts of large-scale potential climate drivers on droughts over four distinct subregions in Canada. Another study by Gao et al. (2017) used BDL to investigate the dynamic impact of IOD, ENSO4.0, PDO, North Atlantic Oscillation (NAO), and Atlantic Multi-decadal Oscillation (AMO) over extreme regional precipitation of China during 1960-2014. However, none of the studies used the BDL model over Pakistan, even though very few research studies have been used the BDL model for droughts analysis. The mathematical equation for BDL-model can be defined as follows (Gao et al. 2017; Yang et al. 2020):

$\left\{\begin{array}{lr}y_{t}=a_{t}+x_{t} \beta_{t}+v_{t}, & v_{t} \sim N\left(0, V_{t}\right) \\ \alpha_{t}=a_{t-1}+\omega_{\alpha, t}, & \omega_{\alpha, t,} \sim N\left(0, \omega_{\alpha, t}\right) \\ \beta_{t}=\beta_{t-1}+\omega_{\beta, t}, & \omega_{\beta, t,} \sim N\left(0, \omega_{\beta, t}\right)\end{array}\right.$ 
where $y_{t}$ indicate response variable with respect to drought index, $x_{t}$ is the covariate in term of climate pattern, $\alpha_{t}$ and $\beta_{t}$ represent the dynamic intercept and slope coefficient at time $t$, respectively, whereas the error sequences $V_{t}, \omega_{\alpha, t}$, and $\omega_{\beta, t}$ are independent, both within them and between them.

\subsection{Statistical validation approach}

Furthermore, the Pearson's correlation coefficient $(r)$, normalized Root Mean Square Error (nRMSE), and Mean absolute Error (MAE) statistics were applied for the calibration and validation of BDL model performance. The calculated statistical equation of the metrics is presented in equations from 16 to 18:

$$
\begin{aligned}
& r=\frac{\sum_{k=1}^{n}\left(O_{i}-\overline{O_{l}}\right)\left(M_{i}-\overline{M_{l}}\right)}{\sqrt{\sum_{k=1}^{n}\left(O_{i}-\overline{O_{l}}\right)^{2}} \sum_{k=1}^{n}\left(M_{i}-\overline{M_{l}}\right)^{2}}, \\
& n R M S E=\sqrt{\frac{1}{N} \sum_{k=1}^{N}\left(M_{i}-O_{i}\right)^{2}}, \\
& M A E=\frac{1}{n} X \sum_{i=1}^{n}\left|O_{i}-P_{i}\right|
\end{aligned}
$$

where, $M$ and $O$ indicate the large-scale climate indices and observed SPEI time series, respectively. Similarly, $i$ denote simulated observed pairs, and $n, k$ is the total number of those pairs being assessed. In Eq. $18, O_{i}$ and $P_{i}$ refers to $i_{t h}$ climate indices and SPEI series, and $n$ indicates the number of data. The earlier studies have widely used these statistical metrics for model validation and analysis (Ayantobo and Wei 2019; Park et al. 2020; Feng et al. 2020).

Based on the evaluation metrics shown in Table S2, the seven large-scale climate indices were applied as a potential driver for drought analysis over Pakistan. The overall statistical validation for those climate indices is in line with earlier studies (Ain et al. 2020; Yang et al. 2020; Feng et al. 2020; Shah and Mishra 2020).

\subsection{Jointly seasonal droughts return period}


The seasonal drought is determined by estimating the SPEI for a time-ratio equivalent to the last months seasonal time span of the corresponding season. We used 6-month SPEI index for the analysis of Rabi and Kharif seasons drought over Pakistan. Seasonal maxima series of SPEI were employed to calculate the return period in seasonal SPEI values by using frequency analysis. In our case, we considered SPEI values $\leq-0.5$ as a drought, and years with no droughts are replaced by zero. We preferred drought frequency analysis based on non-zero values and non-exceedance probability $\left(F^{\prime}\right)$ that is adopted in account of zero values,

$F^{\prime}=q+(1-q) F$

where $F$ indicates non-exceedance probability value attained by applying frequency analysis, and $q$ is the probability of zero values computed as the ratio of the number of time intervals without drought occurrences to the total number of recording period (Ahmed et al. 2018; Mohsenipour et al. 2018). In our study, we fitted the SPEI values of Rabi and Kharif seasons with Normal, Lognormal, Weibull, Gamma, and Extreme Value-I distributions. KolmogorovSmirnov (KS) test was applied to assess the goodness of fit for a particular distribution. The KS test statistics indicated that the null hypothesis of sample distribution alike to Lognormal distribution, which cannot be denied for any seasonal SPEI series. Thus, the Log-normal distribution is applied for the assessment of seasonal droughts.

\section{Results}

\subsection{Spatial pattern of annual and seasonal drought}

Figure 2 illustrates the spatial distributions of SPEI index on seasonal (Rabi and Kharif) and annual timescales in the region, during 1983-2019. During Rabi season (Fig. 2a), the northeastern and southern parts of the country experienced the largest increased from -0.52 to 0.05 in drought severity over few dominant stations of the arid region. The result indicates that the increase in Rabi season observed over the arid to semi-arid regions, which are 
historically more prone to drought hazard. However, no substantial change is detected in drought severity during Rabi season over the northern foothill's because it is the monsoon and western disturbances (WD) core region of the country. In Kharif season (Fig. 2b), most stations show a significant increase in drought severity, except the stations located in northeastern, while few stations exhibit a significant decrease in SPEI with the amount of -0.15 to 0.31 , respectively. An increase in the drought severity is evident in the southern and central parts of the country. A decrease in drought severity is noticeable (increase in Kharif SPEI) ranging from -0.19 to 0.31 over few stations of the north-eastern part of the country. Whereas the Kharif season is mainly influenced by north-eastern monsoon in that region, originates from the Bay of Bengal over the foothills of Himalayan and enter in north-eastern part of the country.

The annual SPEI analysis depicts increasing and decreasing patterns of drought severity across Pakistan during 1983-2019 (Fig. 2c). The south-eastern and central parts of the country exhibited the highest drought severity with an amount of -0.18 to -0.12 over arid to semi-arid regions of the country. For instance, significant decrease in annual SPEI is evident over northern and south-western parts of the country, which is dominated by westerlies monsoon regions. It can be inferred from the findings that the drought severity would rise in the region due to global warming, where the larger risk is associated with arid and semi-arid regions (Fig. S1).

\subsection{Spatial distribution of annual and seasonal drought trends}

The spatial distribution of the SPEI trends during Rabi season, Kharif season, and annual timescale is shown in Fig. 3. The light-yellow dots in the figure depict the significance of increasing and decreasing trend at the 95\% confidence level. In Rabi season (Fig. 3a), the negative trend is obvious with a significant rise in drought severity over the major portion of 
the country (increase in negative SPEI), however, it is observed that a significant increase in Rabi SPEI is dominant over arid and semi-arid regions, which are highly vulnerable to severe droughts. On the other hand, the result indicates that 31 stations depict negative trends while 22 stations show positive trends during 1983-2019. The peak negative trend was evident at Nokkundi (-1.50), Kalat (-1.12), D.I. Khan $(-0.81)$, and Zhob $(-0.41)$ stations, while the maximum positive trend was noticed at Khanpur (-0.93) and Parachinar (-1.25) stations. Moreover, no substantial change is observed in drought severity during Rabi season in the northern foot-hills region.

The Kharif season trend depicts an increasing (decreasing) trend at 29 (24) stations during the study period (Fig. 3b). The majority of the stations show a significant increase in drought severity compared to a decrease in SPEI values suggesting that Kharif droughts are more severe and increased over the target region in recent decades. The increased Kharif trend is evident in the southern part (Fig. S1), while increasing drought severity is observed in the country's north-eastern corner. The positive trends were mostly noticed at Gupis, Parachinar, Risalpor, Peshawar, Kohat, Mianwali, Sargodha, Barkhan, Khanpur, and Rohri stations ranging from 0.75 to 1.03 , respectively. At the same time, the highest negative trend was detected at Balakot, Kakul, and Kalat stations with a decreasing amount of -0.84 and 0.45, respectively. Furthermore, an increase (decrease) in Kharif SPEI (drought severity) trend at the rates of 0.15 to 0.75 is evident in some of the stations, where mostly the Kharif season precipitation is influenced by north-eastern monsoon.

During the annual SPEI trend analysis (Fig. 3c), the result indicates an increasing (decreasing) trend in the 26 (27) stations, respectively. The majority of the stations located at plain areas reveal a positive trend in SPEI index (in comparison to high latitude stations) due to their dynamic nature. The possible reason for such variability could be the limitations of hydrometeorological data or poor management of stations over complex mountainous regions. 
Some of the stations revealed a negative trend, whereas, the majority of the stations show positive trends situated in the south-eastern and western parts of the target region. The trend results further explored that maximum negative trends were observed at D.I. Khan $(-2.03)$, Kalat (-1.84), Nokkundi (-1.73), Panjgur (-1.64), and Kakul (-1.43) stations, while the maximum positive trends were evident at Parachinar (2.05), Bunji (1.35), and Faisalabad (1.20) stations, respectively. The analysis of modified Mann-kendall (modified-MK) trend test shows that a total of 15 stations passed the significant test, out of which 8 stations have a negative trend, while 7 stations have been detected a significantly positive trend.

\subsection{Temporal trends at the annual and seasonal scale}

Figure 4 shows the temporal trends (1983-2019) in the SPEI values during two cropping seasons of Rabi and Kharif, and on an annual timescale. The blue line indicates the amount of drought trends in the respective seasonal and annual timescale, while the red line shows the best-fit regression line. The figure clearly indicates a significant decreasing trend in the Rabi and Kharif seasons, however, the annual variability is different somehow. In Rabi season (Fig. 4a), the seasonal variability appeared to be decreasing with a regression coefficient of -0.31 , which is highest amongst all timescales. The highest Rabi season (dry years) have been recorded during 1994, 2003, and 2014 (1984, 1989, and 2010). In the Kharif season (Fig. 4b), a relatively slight decrease in trend as depicted by a regression coefficient of -0.84 with dry and wet years appeared, possibly causing upward (downward) trends. The driest (wettest) years of the Kharif season were 1984, 1994, and 2003 (1986, 1995, and 2011). On an annual timescale (Fig. 4c), the smallest decreasing trend is evident with a regression coefficient of 0.86 for the study region. Moreover, the highest (lowest) annual dry and wet years have been observed during 1984, 1991, 1994, 2003, and 2010 (1986, 1988, 1995, 2004, and 2014) in the target region. 
From Fig. 4, it can be elucidating that regional variability in seasonal drought (Rabi and Kharif) over Pakistan is obvious during 1983-2019. The extent of regional drought variability could be associated with the geographical location, monsoon circulation patterns, and/or large-scale climate indices. The temporal trend over the Asian and Indian monsoon system showed a strong variation at different time scale; from monthly, inter-annual, seasonal, and annual time scale.

\subsection{Mutations in temporal trends at the annual and seasonal scale}

To document the abrupt changes in seasonal temporal trends and annual SPEI time series, the secular SQMK trend test was applied (Fig. 5). The progressive and retrograde series were attained corresponding to the statistical significance level $\alpha=0.05$; whereas the red line shows the progressive series, the dashed blue line denotes retrograde series, and the yellow lines represent the confidence level. The point at which the red and blue lines intersect shows an abrupt change in the time series trend. The progressive series suggests an initial increase in Rabi season from 1990 to 2000, indicating an abrupt increasing trend (Fig. 5a). In the last decades, a mixed behavior of upward and downward shifts has been observed in Rabi season. Though, a sharp decrease was noticed from 2001 to 2014, which suggests an abrupt decreasing trend.

In Kharif season (Fig. 5b), the trend appeared to be showing a decreasing pattern during the initial study period, however, a rapid rise in the middle years has been observed. The overall trend increased with significant abrupt shifts that appeared during 1991-2001 with two turning points during 1995 and 2016. In the annual trend (Fig. 5c), the abrupt negative changes were detected for the first decade, whereas, a rapid increase in the middle and later years suggesting an abrupt increasing trend. The annual trend is increasing with a 
significant increase that appeared during 1991-2001 with two turning points during 1997 and 2014, respectively.

\subsection{Composite analysis}

To assess the seasonal drought variability and its relationship with large-scale climate indices a composite analysis was performed. To do so, the regional scale monthly, and annual 6month robust SPEI index was developed at the interannual scale. The years with deviation above/below \pm 1 were chosen as dry and wet. A total of 8 years each were selected as dry and wet years for seasonal and annual timescales over Pakistan 1983-2019 as shown in Table S3.

Composites anomalies of geopotential height $(850 \mathrm{hPa})$, wind speed, $2 \mathrm{~m}$ air temperature, and relative humidity $(850 \mathrm{hPa})$ for seasonal and the annual timescale over Pakistan are given in Fig. 6 and S2. During Rabi dry years (Fig. 6a), a relatively weak subtropical jet is observed over the target region, while WD shows a dominant pattern, exhibiting a negative anomaly during dry years. A similar pattern can be seen for $2 \mathrm{~m}$ air temperature and relative humidity, further clarifying dry conditions with elevated air temperature anomalies due to weak precipitation (Fig. S2). This negative anomaly is associated with strong east-western westerlies, transporting moisture from the Bay of Bengal, and the Arabian Sea trajectory to the northern hemisphere during Rabi dry years. A similar pattern can be seen for Rabi wet years (Fig. 6b), suggesting a negative anomaly during wet years. It is observed that the anticyclone westerly pattern (Tibetan Plateau) plays a significant role in transporting moisture incursion from the Bay of Bengal, which enhances the wet conditions in the region. We find that the development of the significance moisture flux convergence is mainly associated with the Tibetan Plateau's anticyclonic pattern, causing wet conditions over the study region. 
During Kharif dry years (Fig. 6c), the subtropical and easterly jets appeared to be pushing the oceanic moisture-laid winds towards the continental landmass. The anomalous dry pattern is evident over South Asia (SA) western parts that engulfs Pakistan with enhanced wind speed, underlying dry conditions. On the other hand, the anomalous geopotential height is obvious over western SA that includes Pakistan, with enhanced relative humidity and reduced air temperature (Fig. S2), indicating increased precipitation. The anticyclonic pattern appeared to be moved to Bay of Bengal region, strengthening sub-tropical jets intensity further into continental land masses. A similar pattern can be seen for Kharif wet years (Fig. 6d), suggesting an increased anomalous pattern over the Tibetan Plateau and foothills of Himalayan, which is mainly responsible for south-western summer monsoon in the region.

On the annual timescale, this analysis further clarifying the dry and wet conditions over SA, including Pakistan. During dry years (Fig. 6e), the continental landmass of SA, predominantly southern and western parts of Pakistan, is under a robust anticyclonic pattern, which is associated with descending wind component and increased geopotential height anomalies. Moreover, a similar pattern can be seen for relative humidity and $2 \mathrm{~m}$ air temperature, which further clarifying dry conditions, with an increase in air temperature caused by decreasing precipitation (Fig. S2). A relatively weak geopotential height anomaly is evident over western Pakistan during wet years, with enhanced relative wind speed (Fig. 6f).

Figure 7 shows the differences (1983-2000 and 2001-2019) between $2 \mathrm{~m}$ air temperature, geopotential height $850 \mathrm{hPa}$, and relative humidity at $850 \mathrm{hPa}$, wind speed, and soil moisture over SA. In our analysis, the first period (1983-2000) is subtracted from the final period (2001-2019) to represent the study area difference. Fig. 7a indicates that the air temperature in the north-western part of the SA is obviously higher than that in the southeastern parts, which may cause the indicator of extreme regional temperature. The results 
indicated increasing trends of warm temperature events over the northern parts of Pakistan. Likewise, Fig. $7 \mathrm{~b}$ represents the variations between wind speed and geopotential height at $850 \mathrm{hPa}$ over SA, indicating less amount of wind speed over northern Pakistan, while increasing wind speed is obvious in the southern parts. The increased geopotential height at $850 \mathrm{hPa}$ is observed over the foothill's mountainous region with an amount of $6-8 \mathrm{gpm}$, while the constrained geopotential height at $850 \mathrm{hPa}$ was detected in the south-western parts of Pakistan, which fluctuating from 8 to $10 \mathrm{gpm}$, respectively. Such uncertainties of increase/decrease in geopotential height at $850 \mathrm{hPa}$, and low/high wind speed may be linked with the increasing (decreasing) trends of extremely high temperatures over the target region.

Similarly, Fig. 7c indicated that the soil moisture is decreased over the northwest parts of the study region, while an increase in soil moisture was found in the southern parts. Notably, a decreasing trend of soil moisture is evident over the target region, suggesting a lack of precipitation and higher temperature intensity in the study area. Moreover, Fig. $7 \mathrm{~d}$ shows that the relative humidity at $850 \mathrm{hPa}$ in the southeast part of Pakistan is obviously higher than that in the southeast and central parts of the SA. This instability could possibly associate with the increased frequency and intensity of temperature extremes over the study region.

The drought return period further clarifies the results obtained in the previous section for Rabi and Kharif seasons over Pakistan. We used the average moving window for calculating return periods over the analysis period of 1983-2019 (Fig. 8). The return periods of drought during seasonal and annual timescales are found in the range of 2-5 (mild), 6-10 (moderate), 11-20 (severe), and 21-35 (extremely severe) years, respectively. During Rabi season (Fig. 8a), the relative changes of 2-5 years return period of drought severity are obvious over most stations, however, the north-eastern part of the country exhibits severe to an extreme severe return period of drought severity. Few stations in eastern Pakistan detected 
a severe 11-20 years return period of drought severity, suggesting a gradual decline in SPEI values in recent years. In Kharif season (Fig. 8b), a fluctuation in the severe drought return period (6-10 and 10-20 years) is dominant over semi-arid and arid regions of the study area, which is historically more prone to droughts hazard. Moreover, the northern and southeastern parts of the region observed extreme severe return periods, indicating that the frequency of severe drought is high during Kharif season. Similarly, during the annual timescale an obvious increase in drought severity over arid region is appeared (Fig. 8c), particularly in few stations of the eastern part exhibit extreme severe return periods. Overall, severe to extreme droughts return periods are found to decrease gradually over time in the majority of the stations. It can be inferred from figure results that increasing temperature in most parts of the country could decrease SPEI values and thus increase the frequency of droughts.

\subsection{Relationship between seasonal SPEI and large-scale climate indices}

We calculated the Pearson's correlation coefficient to obtain the preliminary outlook of the relationship between all the meteorological stations of seasonal SPEI and each selected climate indices over Pakistan (Fig. 9). Overall, DMI and Niño4 were relatively negatively correlated with growing season SPEI, while anomalous SST and Sunspot exhibit a strong positive correlation with SPEI over the country's majority stations. While the rest of the climate indices correlation coefficient vary from lagged month to month. For instance, ENSO4.0 had negative associations with SPEI in adjacent months (Sept. and Jan.) of the growing season while have shown positive correlations with previous months. On the other hand, IOD exhibit a strong negative correlation in both Rabi and Kharif seasons.

Furthermore, the italic number under each correlation coefficient value shows the number of meteorological stations with a significant correlation over Pakistan. From the 
analysis, there were 53 meteorological stations where DMI, Niño4, and SST in January had a substantial association with Rabi season SPEI. Sunspot in antecedent December and March (Rabi season) and PDO in antecedent July had also significantly interrelated over many stations. These large-scale climate indices of the earlier year could also have the potential to influence the growing (Rabi and Kharif) season drought conditions of the present year. For example, the absolute $r$ values were small and generally around zero, suggesting that the association between SPEI values and Climate drivers were very weak. Though the Pearson's correlation only measures the linear relationships between two datasets series. In the subsequent analysis, we may use BDL model to explore other relationship (e.g. non-linear).

Figure 10 revealed the appraised dynamic regression slope coefficients of seven climate drivers on two distinct seasons of Rabi and Kharif, and annual SPEI. Fig. 10(a) showed that the association between DMI and SPEI is obvious during Rabi season and exhibit positive change before 1987 to negative until 2017. Furthermore, DMI was negatively correlated with SPEI during Kharif season before 1980s (Fig. 10h), while a positive increase was found during 1990s and 2010s. The slope showed a decadal variability for the annual timescale and gradually changed from negative to positive (Fig. 10o). In addition, the DMI slope coefficients tend to approach 0 before 2010s, suggesting that the effects of the DMI weakened during both seasons of Pakistan in recent decades.

The most important interannual climate pattern of ENSO4.0 plays an important role in climate variability around the globe. In Pakistan, El Nino phase is mainly related with warmer and drier winters, while La Nina has the vice-versa effect. The results further explored the time-varying impacts of ENSO4.0 on seasonal droughts in Pakistan. An obvious negative and positive slope coefficient during Rabi and Kharif seasons are found in 20102015 (Fig. 10b, i), while the strong impact of El Nino in Rabi season leading to a substantial decline in SPEI index during 2010-2015, implying severe droughts of 2010-2015 in southern 
Pakistan. For annual timescale (Fig. 10p), ENSO4.0 slope coefficient exhibit incline above 0 after 1990s, indicating that ENSO4.0 has a strong influence during annual timescale in recent decades over Pakistan.

For IOD, the slope coefficient of Rabi season varies from positive to negative during the 2000s (Fig. 10c), while a similar pattern can be seen for Kharif season where IOD depicts a negative correlation with SPEI but its influence is decreased from 2000 to 2019 (Fig. 10j). Both seasons are found under the two troughs circa 2000, implying that IOD's effect was stronger at that time. Similar pattern can also be seen for the annual timescale, further clarifying IOD's effect across Pakistan (Fig. 10q). Our analysis shows that IOD has a relative negative association with the SPEI series, suggesting that a positive IOD attribute to the drier conditions in the region.

Moreover, Niño4 depicts a predominantly negative impact on the SPEI during Rabi season over 2000-2019 (Fig. 10d), while persistent negative and positive behavior can be seen for Kharif season (Fig. 10k). Typically the weak influence of Niño4 have been found for both seasons, whereas, the correlation for Rabi season evident a phase change circa the 2000s, and the effect of the Niño4 for Kharif season was mettle after 2005, inferring a decrease in the strength and could possibly phase change in near future. In addition, the predominately positive slope coefficient in annual timescale (Fig. 10r), SPEI is expected to decline, which could result in drier climate in the southern and western Pakistan.

During PDO, the slope coefficient increased from negative to positive circa of 2000s during Rabi season (Fig. 10e), while the opposite association is found for the Kharif season in 2010s can be seen in Fig. 10l. The relatively weak influence of PDO in Rabi season over the years, even though it remains negative. Nevertheless, the annual timescale's slope coefficient changed the circa of 2010s from negative to the positive phase (Fig. 10s). On the other hand, 
the PDO warmer phase after the 2000s with respect to a negative slope contributing dryer conditions for Rabi season, though the cool phase (2000-2016) depict positive correlation and wetting conditions during Kharif season.

The influence of SST fluctuates from negative to positive during both Rabi and Kharif seasons in 1990s and 2000s, respectively. During Rabi season, a circa appeared in the 1990s (Fig. 10f), suggesting a stronger impact of SST at that period, while the effect is decreasing after 2000s to a minimum point. Moreover, the slope coefficients tend to increase, indicating a emphasizing influence of SST over Kharif season (Fig. 10m). The correlation fluctuates during 1990-2019 for annual timescale and depicts a positive slope after 1990s (Fig. 10t). The SST is a leading and potential climate driver influencing the summer temperature in southern and western Pakistan, where summer tends to be warmer and drier when SST is positive and vice versa.

Distinct effects of sunspots on SPEI appeared relatively stable and predominantly negative to positive for Rabi season, Kharif season, and annual timescale, however, during Rabi season, the impact changed negative during the late 1980s and 1990s, while an enhanced positive slope were detected during 2010s (Fig. 10g). It can be remarked that the slope coefficient tends to incline after the 2000s for both seasons and annual timescale, inferring that the influence of sunspots has reinforced in the last few decades. Furthermore, sunspots relatively show a negative relationship with the SPEI from 1980s to 2010s at all scales. Further clarifying that increase sunspots could lead to a decline in SPEI, depicting that the periods with high sunspots amount are more likely to occur dry events in the region.

\section{Discussion}

This study aims to provide a comprehensive assessment of climate change influence on seasonal drought and its potential drivers across Pakistan, during 1983-2019. The Rabi and 
Kharif are evaluated as drought seasons in Pakistan, using modified-MK, SQMK, SS, Linear regression, drought return period, correlation coefficient, nRMSE, and BDL model. Overall, the results inferred that most of the stations across Pakistan exhibited a rise in drought severity during Kharif season and annual timescale, especially those located in arid southeastern and northern parts of the region. The increase/decrease in these seasons and overall variability is somehow agreed with the findings of regional studies (Adnan et al. 2016; Gao et al. 2017; Ahmed et al. 2018; Ain et al. 2020). The drought severity and frequency appeared to be shifting from the arid/semi-arid regions towards the country's western humid region. This shift and increase in drought severity altogether can impact the food security with the provision of abundant/less water for rain-fed regions during early/late summer, though the risk of floods/droughts can also be increased and thus need to be seen.

During seasonal and annual timescale drought severity appeared to be somehow complex in reporting the shifts in trends. The Kharif season drought severity is similar to what has been observed at annual timescale, however, such a pattern was relatively weaker during Rabi season. The possible reason could be statistical operations that average/sum the seasonal droughts, and thus such indicators are lost due to a few extreme events in the months with increasing trends or vice versa. The second possible reason could be Asian summer monsoon and/ or WD dominancy during the Rabi season (Rehman et al. 2018; Khan et al. 2020; Adnan et al. 2020; Feng et al. 2020). The positive trend in Kharif season and annual timescale may positively affect agriculture production, water management and built environment in Pakistan. The study results support the findings of the earlier studies at regional and global scales (Ahmed et al. 2018; Guo et al. 2018; Wang et al. 2019; Alamgir et al. 2020; Shah and Mishra 2020). According to Wang et al. (2014), the varying characteristics of severe droughts based on SPEI exhibit significantly increase trend in terms of global drought zones during 1902-2008. Moreover, recent severe climatic changes caused several 
extreme droughts events over many regions of Pakistan (Adnan et al. 2016; Ali et al. 2017; Ahmed et al. 2018; Hina and Saleem 2019; Ain et al. 2020; Naz et al. 2020).

We performed a composite analysis to further explore the role of large-scale atmospheric circulation patterns as a subsequent driver of such trends. A composite analysis was conducted using eight years each for Rabi, Kharif seasons, and for the annual timescale dry and wet drought conditions. During Rabi wet/dry condition, no obvious relationship was observed with DMI and PDO events, as well as with the IOD, ENSO4.0, and SST onset timing as explored for certain regions of SA especially eastern India and central part of Pakistan (Ahmed et al. 2018; Ain et al. 2020; Shah and Mishra 2020). During Kharif season, the SA continent is under strong anticyclonic descending wind propagation accompanied by less cloud liquid water, suppressed relative humidity, and elevated temperature indicating less precipitation and higher temperature in the region. Recently, Ain et al. (2019) investigated seasonal droughts over the Potwar Plateau of Pakistan using large-scale atmospheric circulation as a potential drivers. They found that the positive anticyclonic anomaly over the Tibetan Plateau and their related moisture transport from the Bay of Bengal resulting extreme drying conditions during Kharif season. Moreover, the wet years of Kharif season evident strong subtropical trajectory transport moisture into the inland regions from the oceans, suggesting an obvious increase in relative humidity and suppressed air temperature. The findings infer the possibility that the temperature and precipitation variability over Pakistan has a significant association with large-scale climate indices modes. The seasonal drought trend could be due to climate extreme events, their respective intensity and frequency during each season. Even though the large-scale atmospheric circulation may have some little impact, but the influence of climate change on seasonal drought, is therefore, thoroughly investigated using large-scale climate indices as a potential driver. 
Shah and Mishra (2020) reveal that hydrometeorological droughts often result from anomalous large-scale atmospheric circulation patterns caused by positive phase of ENSO4.0 and IOD over India. Himayoun and Roshni (2019) investigated that the drought characteristics are significantly influenced by ENSO4.0 events throughout the Jhelum basin of India. Moreover, a consistently weaker phase of positive IOD and PDO patterns during the recent severe drought in 2000-2002 deviates from the previous drought which tends to be linked with large-scale connections (Xiao et al. 2019; Ain et al. 2020; Liu et al. 2020). In terms of large-scale inter-connection perspective, the 2000-2005 droughts are changed from previous droughts of southern Pakistan, which confirms our findings based on dynamic association with the large-scale climate indices droughts over Pakistan. According to Rajagopalan et al. (2000) they explored the association of droughts with ENSO over the past summer U.S, and suggested the application of the BDL model to better understand the nonstationary relationship between droughts and ENSO4.0 during the Twentieth century. Meanwhile, Yang et al. (2020) studied the influence of climate drivers on regional drought variability using BDL model. They described that droughts are generally more negatively correlated with PDO and ENSO4.0, while more positively correlated with SST and DMI after the 1980s.

It can be inferred from results that the dynamic impacts of large-scale climate indices on seasonal droughts reveal substantial changes in the relationship across Pakistan. Notably, the ENSO4.0 influence seems relative weakened during Rabi season in the last few decades, particularly after the 2000s. During Kharif season most of the climate drivers appeared with higher negative impacts on drought variability after the 1990s, whereas DMI, ENSO4.0, and sunspots exhibited a phase change in the 1980s, 1990s, and 2010s, respectively. For annual timescale, all climate indices are positively correlated with SPEI except IOD and PDO after the 1990s. 


\section{Conclusion}

The present study attempted to explore the climate change influence on seasonal drought and its potential drivers across Pakistan. The results indicated that most of the stations across Pakistan have shown an increase in droughts severity during Kharif season and on annual timescale, particularly those located in arid south-eastern and northern regions of the study area. It is noticed that temperature and precipitation variability over Pakistan has a significant relationship with large-scale climate indices modes. Seasonal drought could be due to extreme climate events and their respective intensity and frequency during each season, which could be a potential driver. This study's investigations further confirm the impact of large-scale potential climate drivers on seasonal droughts in Pakistan, contributing the favourable changes in the relationship during 1983-2019. The influence of ENSO4.0 is relatively weakened in recent decades across Pakistan, particularly after the 2000 s, however, DMI, ENSO4.0, and sunspots exhibited a phase change during 1980s and 1990s, respectively. During Rabi season, climate patterns usually exerted more negative than positive impact on the drought variability in terms of dynamic regression slope coefficients after the 1990s. For Kharif season, the majority of the climate indices were negatively associated with the SPEI after the 2000s, when DMI, ENSO4.0, and sunspots exhibited a phase change circa 1980s, respectively. On an annual timescale, all climate indices are positively correlated with SPEI except IOD and PDO after the 1990s. In general, a relative decrease in severe and extreme droughts is noticed across Pakistan in the recent few decades, which can be accredited to the regional influence of global warming.

Acknowledgements This work was financially supported by the National Natural Science Foundation of China (41877158). We are thankful to all datasets centres for availing data to use for dynamic mechanism studies, specifically in-situ observation from the Pakistan Meteorological Department (PMD) for providing precipitation and temperature dataset. 
Code Availability Not applicable.

Author Contributions I.U and X.M designed the study, conducted the analysis, and wrote the manuscript. F.S, J.Y, A.B, and S.S contributed in discussion and helped to shape the research, analysis, and writing of the manuscript. B.A.H helped in managing and downloading the data.

Data availability Reanalysis datasets of ERA-5 are available at European Centre for Medium-Range Weather Forecasts (ECMWF), while climate indices data were archived from (https://psl.noaa.gov/data/climateindices/list/).

\section{Declarations}

Conflict of interest All authors declare no competing interest.

\section{References}

Adnan S, Ullah K, Ahmed R (2020) Variability in meteorological parameters and their impact on evapotranspiration in a humid zone of Pakistan. Meteorol Appl 27:1-10. https://doi.org/10.1002/met.1859

Adnan S, Ullah K, Shouting G (2016) Investigations into precipitation and drought climatologies in south central Asia with special focus on Pakistan over the period 19512010. J Clim 29:6019-6035. https://doi.org/10.1175/JCLI-D-15-0735.1

Ahmed K, Shahid S, Nawaz N (2018) Impacts of climate variability and change on seasonal drought characteristics of Pakistan. Atmos Res 214:364-374. https://doi.org/10.1016/j.atmosres.2018.08.020

Ain NU, Latif M, Ullah K, et al (2020) Investigation of seasonal droughts and related largescale atmospheric dynamics over the Potwar Plateau of Pakistan. Theor Appl Climatol 140:69-89. https://doi.org/10.1007/s00704-019-03064-8

Akhtar I ul H, Athar H (2019) Contribution of changing precipitation and climatic oscillations in explaining variability of water extents of large reservoirs in Pakistan. Sci Rep 9:1-14. https://doi.org/10.1038/s41598-019-54872-X

Alamgir M, Khan N, Shahid S, et al (2020) Evaluating severity-area-frequency (SAF) of seasonal droughts in Bangladesh under climate change scenarios. Stoch Environ Res Risk Assess 34:447-464. https://doi.org/10.1007/s00477-020-01768-2

Ali M, Deo RC, Maraseni T, Downs NJ (2019) Improving SPI-derived drought forecasts incorporating synoptic-scale climate indices in multi-phase multivariate empirical mode decomposition model hybridized with simulated annealing and kernel ridge regression algorithms. J Hydrol 576:164-184. https://doi.org/10.1016/j.jhydrol.2019.06.032

Ali Z, Hussain I, Faisal M, et al (2017) Forecasting Drought Using Multilayer Perceptron Artificial Neural Network Model. Adv Meteorol 2017:. https://doi.org/10.1155/2017/5681308 
Anjum MN, Ding Y, Shangguan D, et al (2018) Performance evaluation of latest integrated multi-satellite retrievals for Global Precipitation Measurement (IMERG) over the northern highlands of Pakistan. Atmos Res 205:134-146. https://doi.org/10.1016/j.atmosres.2018.02.010

Ashraf M, Routray JK (2015) Spatio-temporal characteristics of precipitation and drought in Balochistan Province, Pakistan. Nat Hazards 77:229-254. https://doi.org/10.1007/s11069-015-1593-1

Ayantobo OO, Wei J (2019) Appraising regional multi-category and multi-scalar drought monitoring using standardized moisture anomaly index (SZI): A water-energy balance approach. J Hydrol 579:124139. https://doi.org/10.1016/j.jhydrol.2019.124139

Bates BC, Kundzewicz ZW, Wu S, Palutikof JP (2008) Climate Change and Water. Technical Paper of the Intergovernmental Panel on Climate Change (IPCC)

Bayer Altın T, Barak B (2017) Trends and changes in tropical and summer days at the Adana Sub-Region of the Mediterranean Region, Southern Turkey. Atmos Res 196:182-199. https://doi.org/10.1016/j.atmosres.2017.06.017

Chatterjee S, Khan A, Akbari H, Wang Y (2016) Monotonic trends in spatio-temporal distribution and concentration of monsoon precipitation (1901-2002), West Bengal, India. Atmos Res 182:54-75. https://doi.org/10.1016/j.atmosres.2016.07.010

Chen F, Chen J, Huang W, et al (2019) Westerlies Asia and monsoonal Asia: Spatiotemporal differences in climate change and possible mechanisms on decadal to sub-orbital timescales. $\quad$ Earth-Science Rev 192:337-354. https://doi.org/10.1016/j.earscirev.2019.03.005

Curtis S, Adler R (2000) ENSO indices based on patterns of satellite-derived precipitation. J Clim. https://doi.org/10.1175/1520-0442(2000)013<2786:EIBOPO>2.0.CO;2

Dai A (2013) Increasing drought under global warming in observations and models. Nat Clim Chang 3:52-58. https://doi.org/10.1038/nclimate1633

Das J, Jha S, Goyal MK (2020) Non-stationary and copula-based approach to assess the drought characteristics encompassing climate indices over the Himalayan states in India. J Hydrol 580:124356. https://doi.org/10.1016/j.jhydrol.2019.124356

Duffy PB, Brando P, Asner GP, Field CB (2015) Projections of future meteorological drought and wet periods in the Amazon. Proc Natl Acad Sci U S A. https://doi.org/10.1073/pnas.1421010112

Ehsan MA, Nicolì D, Kucharski F, et al (2020) Atlantic Ocean influence on Middle East summer surface air temperature. npj Clim Atmos Sci 3:5. https://doi.org/10.1038/s41612-020-0109-1

Endris HS, Lennard C, Hewitson B, et al (2019) Future changes in rainfall associated with ENSO, IOD and changes in the mean state over Eastern Africa. Clim Dyn 52:20292053. https://doi.org/10.1007/s00382-018-4239-7

Feng P, Wang B, Luo J-J, et al (2020) Using large-scale climate drivers to forecast meteorological drought condition in growing season across the Australian wheatbelt. Sci Total Environ 724:138162. https://doi.org/10.1016/j.scitotenv.2020.138162

Gao T, Wang HJ, Zhou T (2017) Changes of extreme precipitation and nonlinear influence of 
climate variables over monsoon region in China. Atmos Res 197:379-389. https://doi.org/10.1016/j.atmosres.2017.07.017

Guo H, Bao A, Liu T, et al (2018) Spatial and temporal characteristics of droughts in Central Asia during 1966-2015. Sci Total Environ 624:1523-1538. https://doi.org/10.1016/j.scitotenv.2017.12.120

Hamed KH, Ramachandra Rao A (1998) A modified Mann-Kendall trend test for autocorrelated data. J Hydrol. https://doi.org/10.1016/S0022-1694(97)00125-X

Haroon MA, Zhang J, Yao F (2016) Drought monitoring and performance evaluation of MODIS-based drought severity index (DSI) over Pakistan. Nat Hazards 84:1349-1366. https://doi.org/10.1007/s11069-016-2490-y

Hersbach H, Bell B, Berrisford P, et al (2019) Global reanalysis: goodbye ERA-Interim, hello ERA5. ECMWF Newsl

Himayoun D, Roshni T (2019) Spatio-temporal variation of drought characteristics, water resource availability and the relation of drought with large scale climate indices: A case study of Jhelum basin, India. Quat Int 525:140-150. https://doi.org/10.1016/j.quaint.2019.07.018

Hina S, Saleem F (2019) Historical analysis (1981-2017) of drought severity and magnitude over a predominantly arid region of Pakistan. Clim Res 78:189-204. https://doi.org/10.3354/cr01568

Hui-Mean F, Yusop Z, Yusof F (2018) Drought analysis and water resource availability using standardised precipitation evapotranspiration index. Atmos Res. https://doi.org/10.1016/j.atmosres.2017.10.014

IPCC (2014) Climate Change 2013 - The Physical Science Basis. Cambridge University Press, Cambridge

Joshi S, Kar SC (2018) Mechanism of ENSO influence on the South Asian monsoon rainfall in global model simulations. Theor Appl Climatol 131:1449-1464. https://doi.org/10.1007/s00704-017-2045-5

Kang D, Lee M-I (2019) ENSO influence on the dynamical seasonal prediction of the East Asian Winter Monsoon. Clim Dyn 53:7479-7495. https://doi.org/10.1007/s00382-0173574-4

Kendall MG (1955) Rank correlation methods, 2nd ed. Oxford, England: Hafner Publishing Co..

Khan N, Sachindra DA, Shahid S, et al (2020) Prediction of droughts over Pakistan using machine learning algorithms. Adv Water Resour 139:. https://doi.org/10.1016/j.advwatres.2020.103562

Khan N, Shahid S, Ismail T bin, Wang X-J (2018) Spatial distribution of unidirectional trends in temperature and temperature extremes in Pakistan. Theor Appl Climatol 18:1-15

Koutsoyiannis D (2003) Climate change, the Hurst phenomenon, and hydrological statistics. Hydrol Sci J. https://doi.org/10.1623/hysj.48.1.3.43481

Liu W, Zhu S, Huang Y, et al (2020) Spatiotemporal Variations of Drought and Their Teleconnections with Large-Scale Climate Indices over the Poyang Lake Basin, China. 
Sustainability 12:3526. https://doi.org/10.3390/su12093526

Mantua NJ, Hare SR, Zhang Y, et al (1997) A Pacific Interdecadal Climate Oscillation with Impacts on Salmon Production. Bull Am Meteorol Soc. https://doi.org/10.1175/15200477(1997)078<1069:APICOW>2.0.CO;2

Marshall GJ (2003) Trends in the Southern Annular Mode from observations and reanalyses. J Clim. https://doi.org/10.1175/1520-0442(2003)016<4134:TITSAM>2.0.CO;2

McBride JL, Nicholls N (1983) Seasonal relationships between Australian rainfall and the Southern Oscillation. Mon Weather Rev. https://doi.org/10.1175/15200493(1983)111<1998:SRBARA>2.0.CO;2

Mishra V (2020) Long-term (1870-2018) drought reconstruction in context of surface water security in India. J Hydrol 580:124228. https://doi.org/10.1016/j.jhydrol.2019.124228

Mishra V, Aadhar S, Mahto SS (2021) Anthropogenic warming and intraseasonal summer monsoon variability amplify the risk of future flash droughts in India. npj Clim Atmos Sci 4:1. https://doi.org/10.1038/s41612-020-00158-3

Mishra V, Thirumalai K, Singh D, Aadhar S (2020) Future exacerbation of hot and dry summer monsoon extremes in India. npj Clim Atmos Sci 3:10. https://doi.org/10.1038/s41612-020-0113-5

Miyan MA (2015) Droughts in asian least developed countries: Vulnerability and sustainability. Weather Clim Extrem. https://doi.org/10.1016/j.wace.2014.06.003

Mohsenipour M, Shahid S, Chung E sung, Wang X jun (2018) Changing Pattern of Droughts during Cropping Seasons of Bangladesh. Water Resour Manag. https://doi.org/10.1007/s11269-017-1890-4

Naz, Dars, Ansari, et al (2020) Drought Trends in Balochistan. Water 12:470. https://doi.org/10.3390/w12020470

Olauson J (2018) ERA5: The new champion of wind power modelling? Renew Energy. https://doi.org/10.1016/j.renene.2018.03.056

Park S, Kang D, Yoo C, et al (2020) Recent ENSO influence on East African drought during rainy seasons through the synergistic use of satellite and reanalysis data. ISPRS J Photogramm Remote Sens 162:17-26. https://doi.org/10.1016/j.isprsjprs.2020.02.003

Rajagopalan B, Cook E, Lall U, Ray BK (2000) Spatiotemporal variability of ENSO and SST teleconnections to summer drought over the United States during the twentieth century. J Clim. https://doi.org/10.1175/1520-0442(2000)013<4244:SVOEAS>2.0.CO;2

Rayner NA, Parker DE, Horton EB, et al (2003) Global analyses of sea surface temperature, sea ice, and night marine air temperature since the late nineteenth century. J Geophys Res Atmos. https://doi.org/10.1029/2002jd002670

Rehman N, Adnan M, Ali S (2018) Assessment of CMIP5 climate models over south Asia and climate change projections over Pakistan under representative concentration pathways. Int J Glob Warm 16:381-415. https://doi.org/10.1504/IJGW.2018.095994

Saji NH, Yamagata T (2003) Possible impacts of Indian Ocean Dipole mode events on global climate. Clim Res. https://doi.org/10.3354/cr025151

Sajjad H, Ghaffar A (2019) Observed, simulated and projected extreme climate indices over 
Pakistan in changing climate. Theor Appl Climatol. https://doi.org/10.1007/s00704-0182573-7

Sen PK (1968) Estimates of the Regression Coefficient Based on Kendall's Tau. J Am Stat Assoc 63:1379-1389. https://doi.org/10.1080/01621459.1968.10480934

Shah D, Mishra V (2020) Drought Onset and Termination in India. J Geophys Res Atmos 125:1-21. https://doi.org/10.1029/2020JD032871

Sneyers R (1990) On the statistical analysis of series of observations. World Meteorol Organ. https://doi.org/10.1016/0169-8095(93)90010-1

Toreti A, Kuglitsch FG, Xoplaki E, et al (2011) A note on the use of the standard normal homogeneity test to detect inhomogeneities in climatic time series. Int $\mathrm{J}$ Climatol 31:630-632. https://doi.org/10.1002/joc.2088

Ullah A, Sun H, Yang X, Zhang X (2017) Drought coping strategies in cotton: increased crop per drop. Plant Biotechnol. J.

Vanlommel P, Cugnon P, Linden RAM Van Der, et al (2004) The Sidc: World Data Center for the Sunspot Index. Sol Phys 224:113-120. https://doi.org/10.1007/s11207-005-65042

Vicente-Serrano SM, Beguería S, López-Moreno JI (2010) A Multiscalar Drought Index Sensitive to Global Warming: The Standardized Precipitation Evapotranspiration Index. J Clim 23:1696-1718. https://doi.org/10.1175/2009JCLI2909.1

Vinayachandran PN, Francis PA, Rao SA (2009) Indian Ocean Dipole: Processes and impacts. Curr Trends Sci 569-589. https://doi.org/http://moeseprints.incois.gov.in/97/

Wang Q, Wu J, Lei T, et al (2014) Temporal-spatial characteristics of severe drought events and their impact on agriculture on a global scale. Quat Int 349:10-21. https://doi.org/10.1016/j.quaint.2014.06.021

Wang Y, Liu G, Guo E (2019) Spatial distribution and temporal variation of drought in Inner Mongolia during 1901-2014 using Standardized Precipitation Evapotranspiration Index. Sci Total Environ 654:850-862. https://doi.org/10.1016/j.scitotenv.2018.10.425

Waqas A, Athar H (2019) Spatiotemporal variability in daily observed precipitation and its relationship with snow cover of Hindukush, Karakoram and Himalaya region in northern Pakistan. Atmos Res 228:196-205. https://doi.org/10.1016/j.atmosres.2019.06.002

Wu Z, Xu H, Li Y, et al (2018) Climate and drought risk regionalisation in China based on probabilistic aridity and drought index. Sci Total Environ. https://doi.org/10.1016/j.scitotenv.2017.08.078

Xiao L, Chen X, Zhang R, Zhang Z (2019) Spatiotemporal evolution of droughts and their teleconnections with large-scale climate indices over Guizhou Province in Southwest China. Water (Switzerland) 11:. https://doi.org/10.3390/w11102104

Yang K, Zhang J (2018) Evaluation of reanalysis datasets against observational soil temperature data over China. Clim Dyn 50:317-337. https://doi.org/10.1007/s00382017-3610-4

Yang Y, Gan TY, Tan X (2020) Spatiotemporal changes of drought characteristics and their dynamic drivers in Canada. Atmos Res 232:104695. 
https://doi.org/10.1016/j.atmosres.2019.104695

Yang Y, Gan TY, Tan X (2019) Spatiotemporal Changes in Precipitation Extremes over Canada and Their Teleconnections to Large-Scale Climate Patterns. J Hydrometeorol 20:275-296. https://doi.org/10.1175/JHM-D-18-0004.1

You QL, Ren GY, Zhang YQ, et al (2017) An overview of studies of observed climate change in the Hindu Kush Himalayan (HKH) region. Adv Clim Chang Res 8:141-147. https://doi.org/10.1016/j.accre.2017.04.001

Yu H, Wang L, Yang R, et al (2018) Temporal and spatial variation of precipitation in the Hengduan Mountains region in China and its relationship with elevation and latitude. Atmos Res 213:1-16. https://doi.org/10.1016/j.atmosres.2018.05.025

Zhang Y, Huang S, Huang Q, et al (2019) Assessment of drought evolution characteristics based on a nonparametric and trivariate integrated drought index. J Hydrol 579:124230. https://doi.org/10.1016/j.jhydrol.2019.124230

Zhong R, He Y, Chen X (2018) Responses of the hydrological regime to variations in meteorological factors under climate change of the Tibetan plateau. Atmos Res 214:296-310. https://doi.org/10.1016/j.atmosres.2018.08.008

Table 1 List of seven large-scale climate indices used in this study during the period of 1983-2019.

\begin{tabular}{|c|c|c|c|}
\hline Index name & Abbreviation & Detail descriptions & Reference \\
\hline $\begin{array}{l}\text { Indian Ocean } \\
\text { Dipole }\end{array}$ & IOD & $\begin{array}{c}\text { An SST dipole between the western and eastern } \\
\text { tropical Indian Ocean }\end{array}$ & $\begin{array}{l}\text { (Vinayachandran } \\
\text { et al. 2009) }\end{array}$ \\
\hline $\begin{array}{l}\text { Niño4-SST } \\
\text { Index }\end{array}$ & Niño4-SST & Mean SST in the Niño4 regions & $\begin{array}{l}\text { (Rayner et al. } \\
\text { 2003) }\end{array}$ \\
\hline $\begin{array}{c}\text { El Niño } \\
\text { Southern } \\
\text { Oscillation } \\
\text { Version-4 }\end{array}$ & ENSO4.0 & $\begin{array}{l}\text { SST anomalies in the central and eastern equatorial } \\
\text { Pacific Ocean }\end{array}$ & $\begin{array}{l}\text { (Curtis and Adler } \\
\text { 2000) }\end{array}$ \\
\hline $\begin{array}{l}\text { Dipole Mode } \\
\text { Index }\end{array}$ & DMI & $\begin{array}{c}\text { Intensity of the IOD is presented by anomalous SST } \\
\text { gradients between the western and the south eastern } \\
\text { equatorial Indian Ocean }\end{array}$ & $\begin{array}{c}\text { (Saji and } \\
\text { Yamagata 2003) }\end{array}$ \\
\hline $\begin{array}{l}\text { Pacific } \\
\text { Decadal } \\
\text { Oscillation }\end{array}$ & PDO & $\begin{array}{l}\text { A long-term ENSO pattern of Pacific climate } \\
\text { variability }\end{array}$ & $\begin{array}{l}\text { (Mantua et al. } \\
\text { 1997) }\end{array}$ \\
\hline $\begin{array}{l}\text { Sea surface } \\
\text { temperature }\end{array}$ & SST & Combined land surface and SST values & $\begin{array}{c}(\text { Saji and } \\
\text { Yamagata 2003) }\end{array}$ \\
\hline Sunspot Index & Sunspot & Monthly sunspot numbers & $\begin{array}{l}\text { (Vanlommel et al. } \\
\text { 2004) }\end{array}$ \\
\hline
\end{tabular}




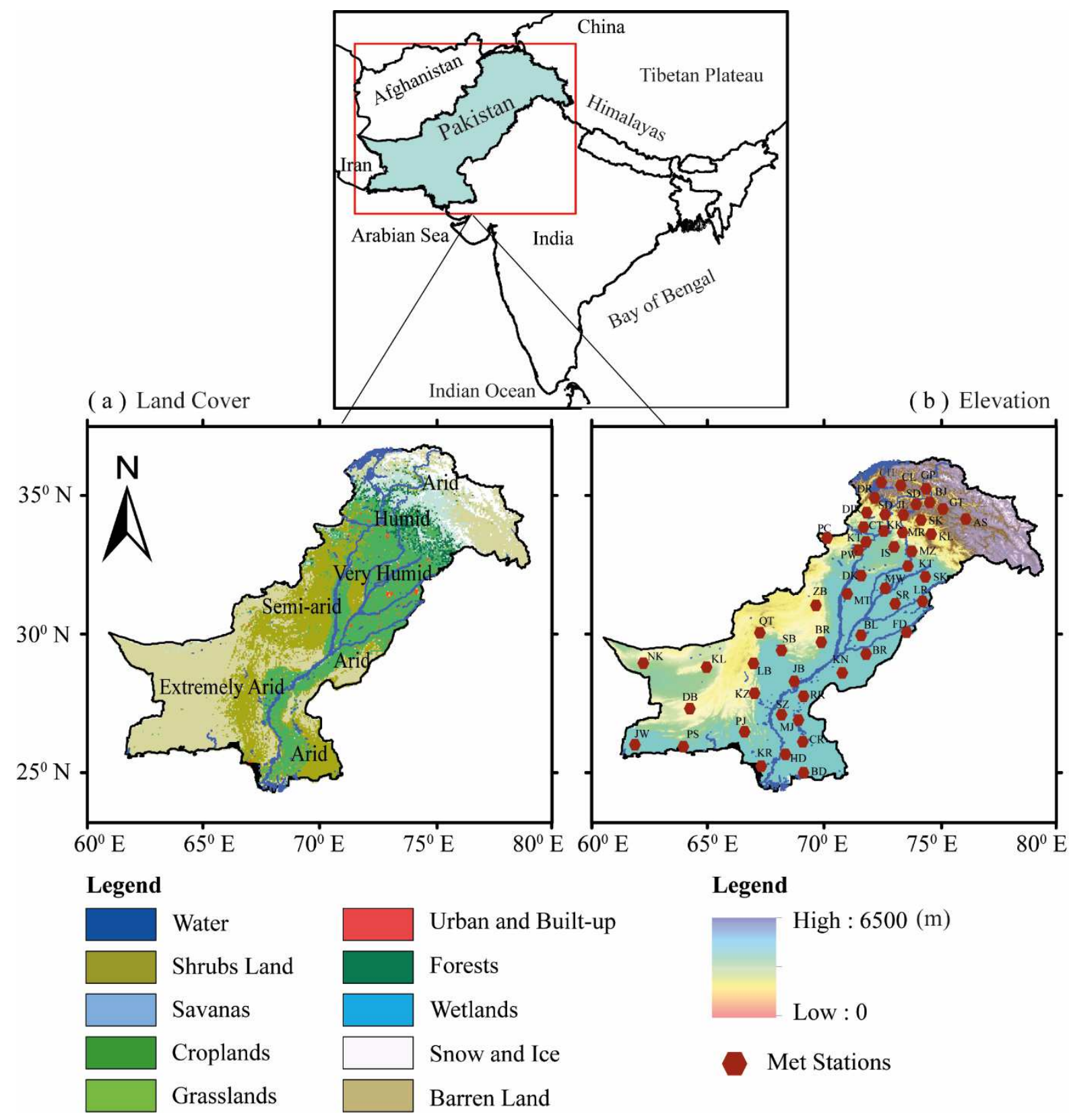

Fig. 1 Location map of the Pakistan showing (a) land cover, aridity classes, and (b) elevation with 53 meteorological stations. 
(a) Rabi Season

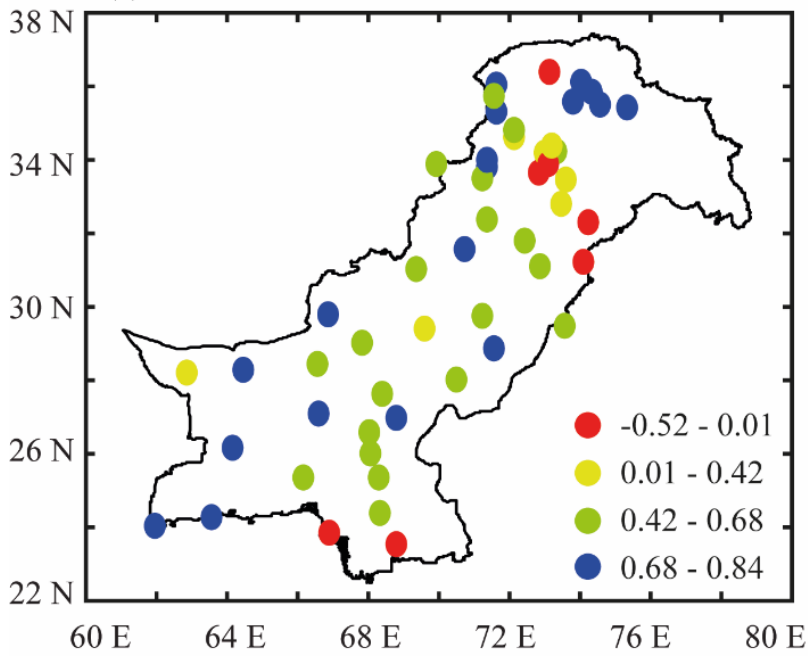

b) Kharif Season

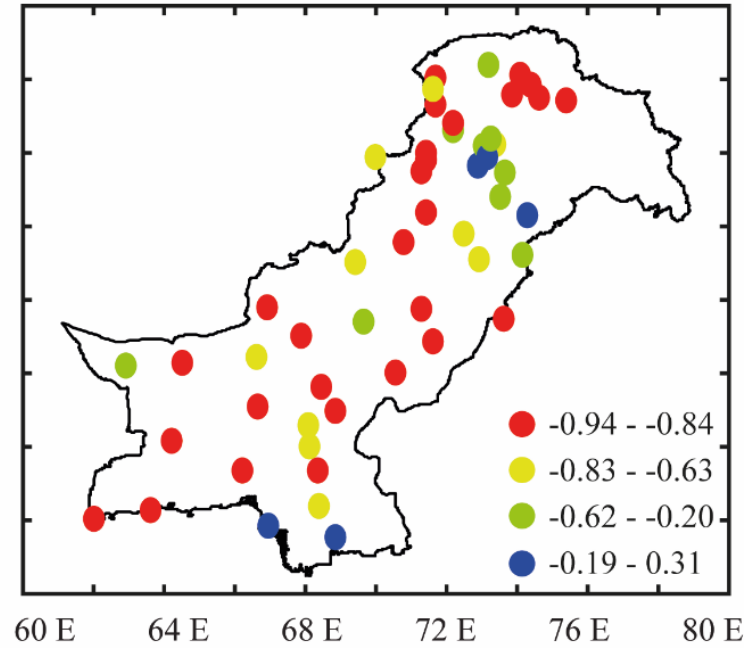

(c) Annual timescale

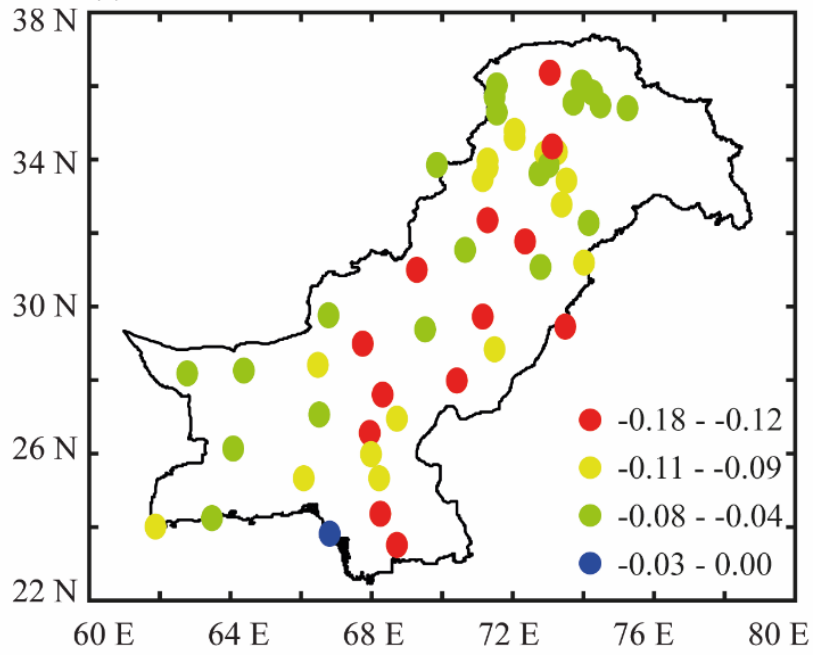

Fig. 2 Spatial pattern of annual and seasonal SPEI (6-month) during 1983--2019 over

Pakistan; a) Rabi season (summer; from May to October), b) Kharif season (winter; from November to April), and c) Annual, respectively. 
(a) Rabi SPEI Trends

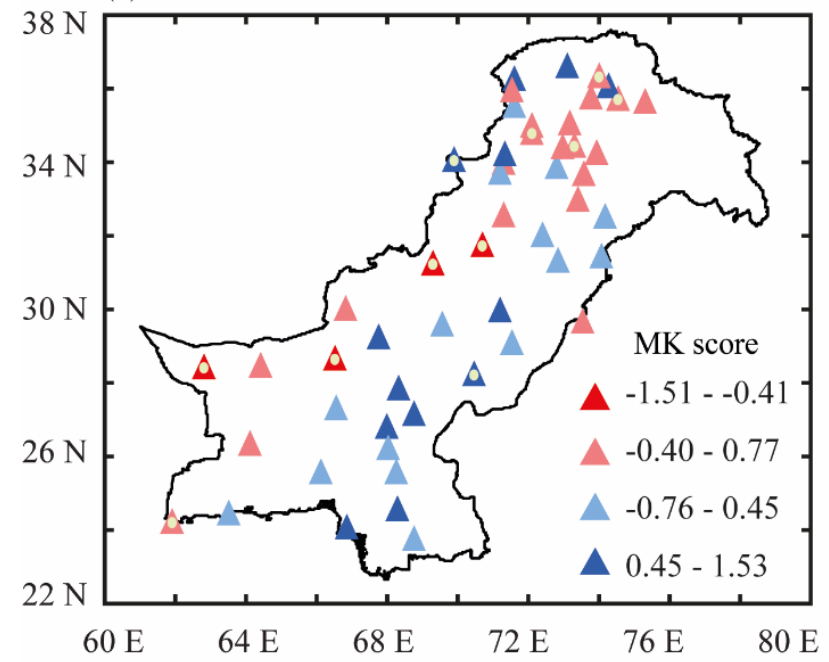

(b) Kharif SPEI Trends

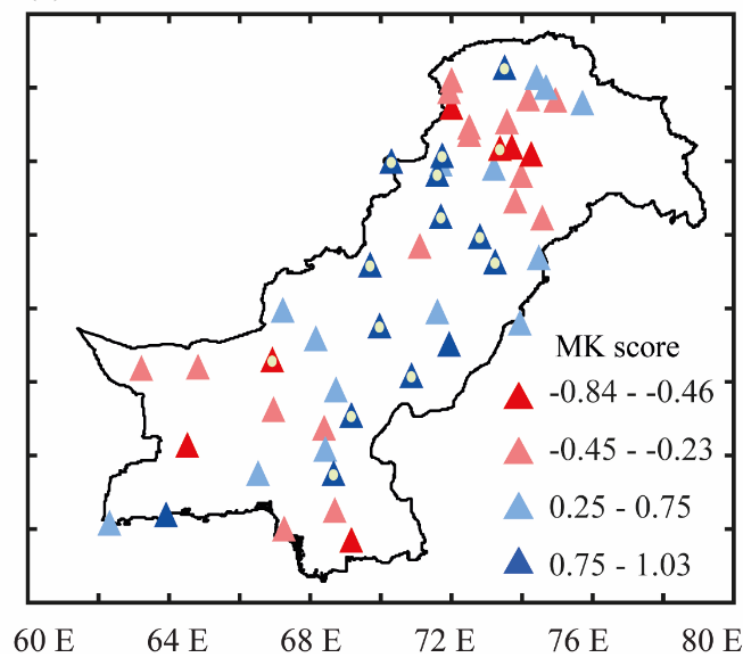

(c) Annual SPEI Trends

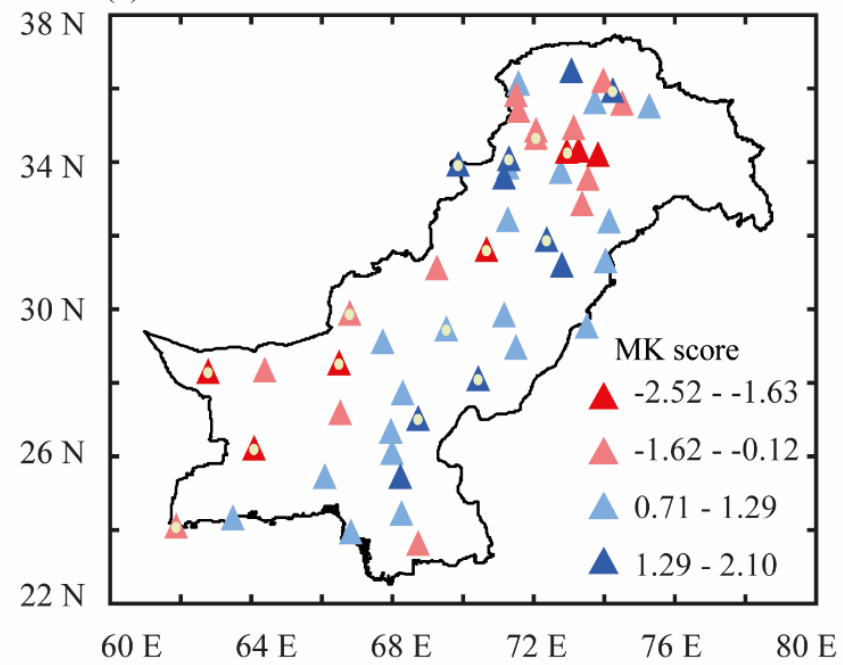

Fig. 3 Spatial distribution of monthly SPEI trends during 1983-2019; a) Rabi season, b)

Kharif season, and c) Annual. The light-yellow dots represent the stations where modifiedMK test passed the significance test at $95 \%$ confidence. 
(a) Rabi Season

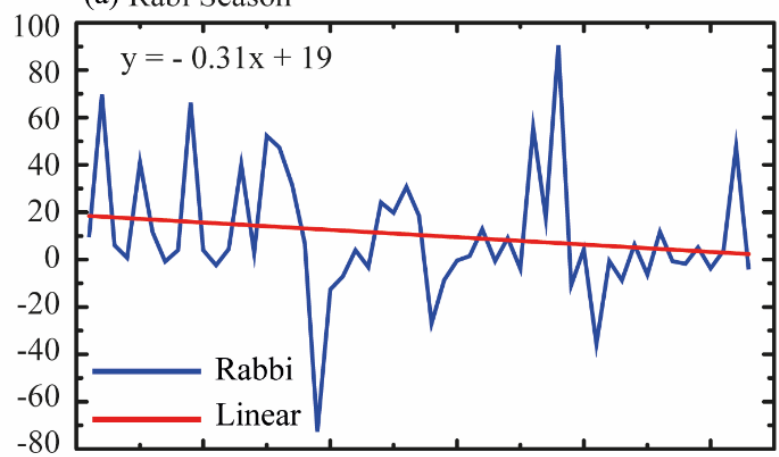

(c) Annual timescale

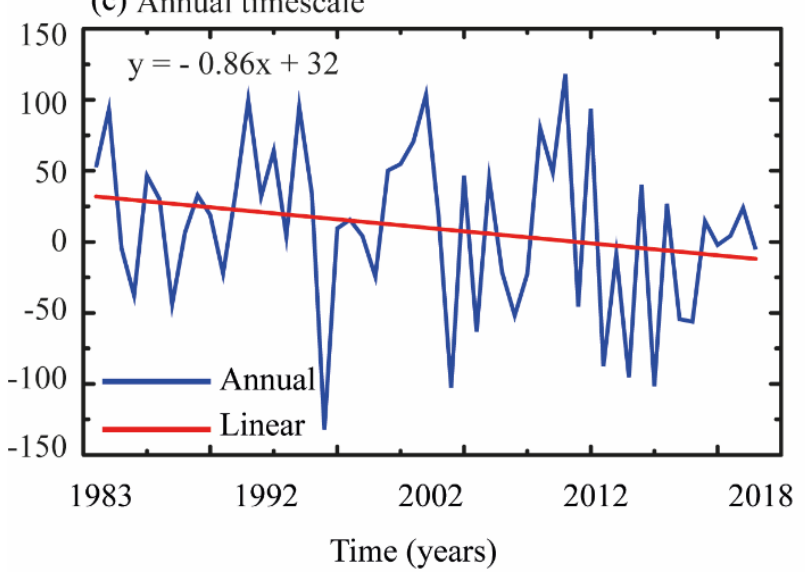

(b) Kharif Season

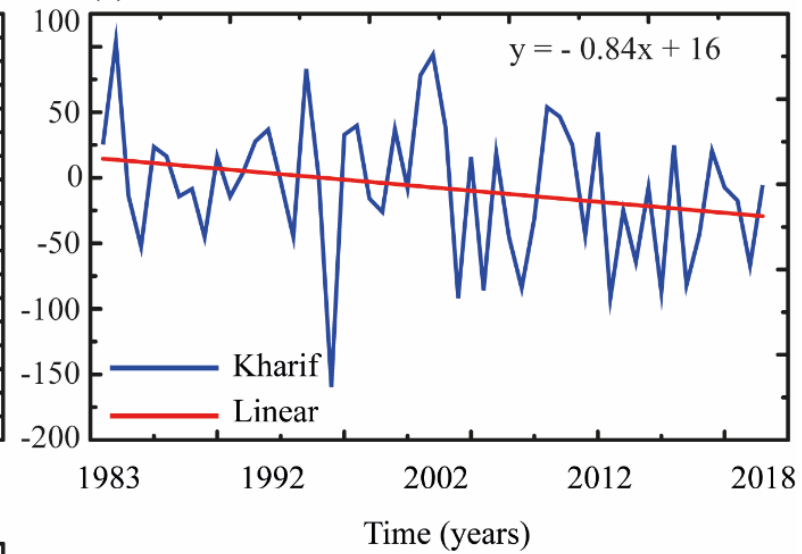

Fig. 4 Linear regression-based trend of annual SPEI during 1983-2019; a) Rabi season, b) Kharif season, and c) annual timescale, respectively. The red line indicates the regression best fit line, and the equation shows the magnitude of the slope. 
(a) Rabi Season

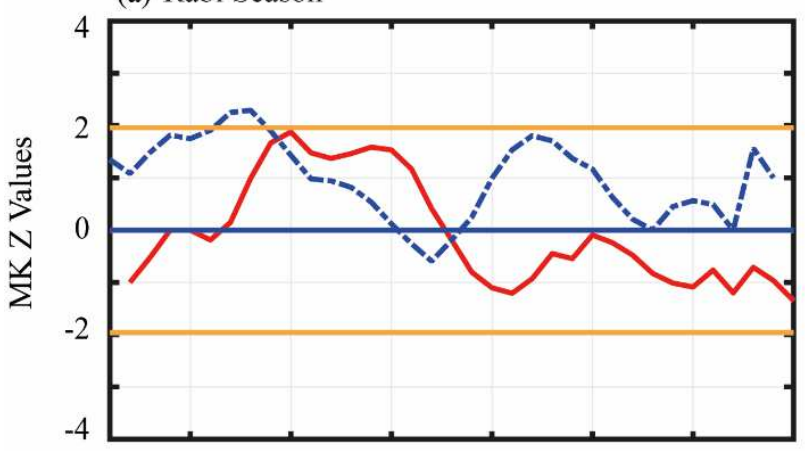

(c) Annual timescale

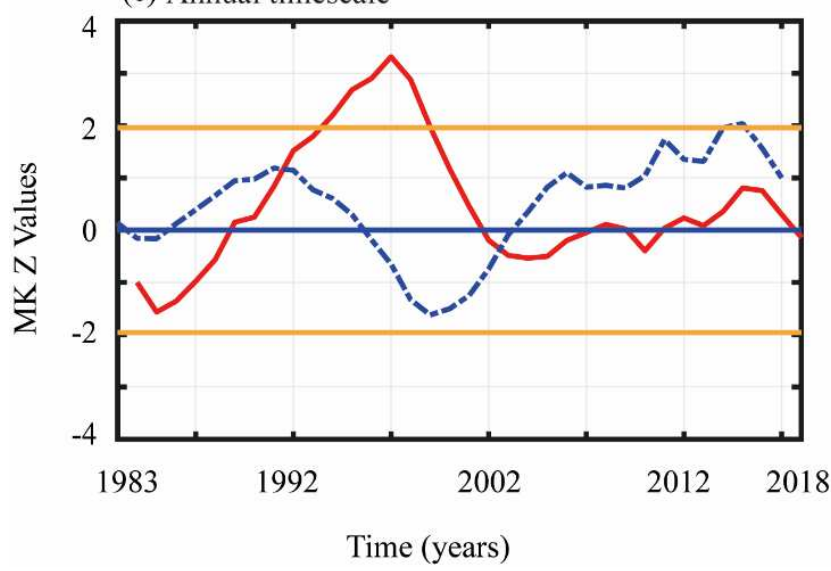

(b) Kharif Season

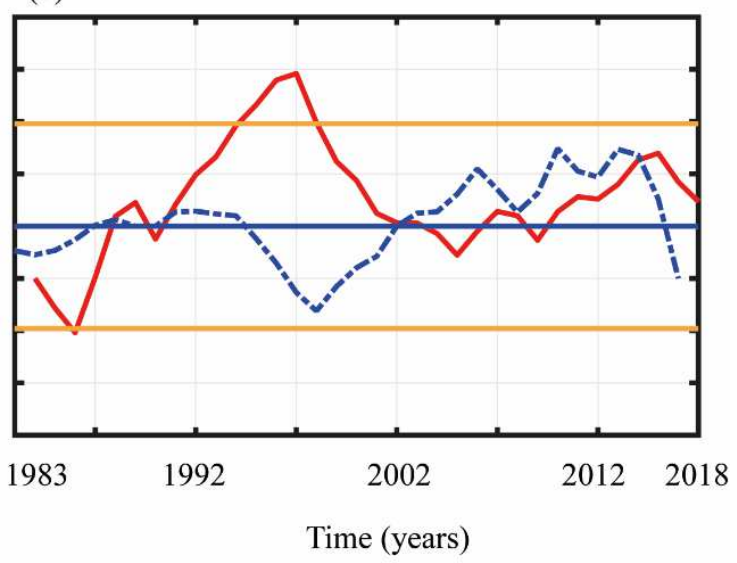

Progressive Series

Retrograde Series

Significance Level

Fig. 5 SQMK trend of annual mean SPEI during 1983-2019; a) Rabi season, b) Kharif season, and c) annual timescale, respectively. 
(a) Rabi Dry years

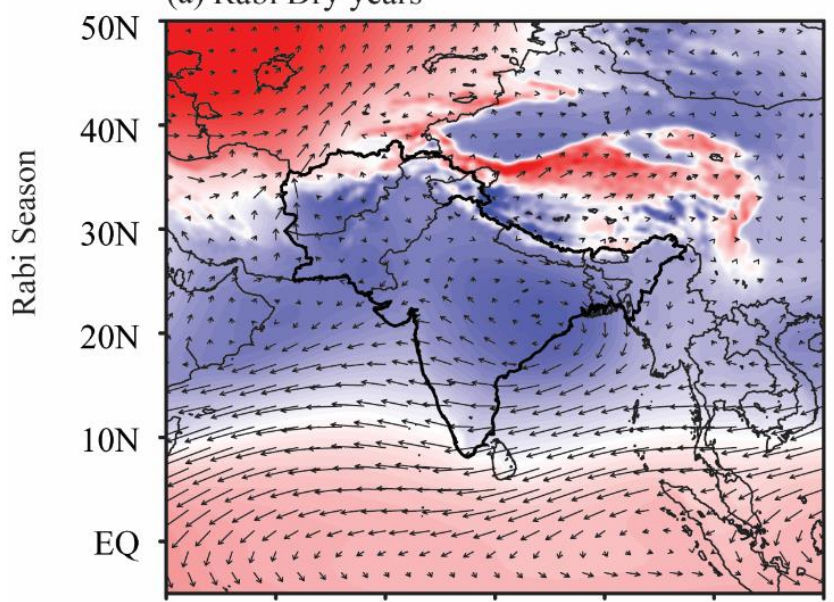

(c) Kharif Dry years

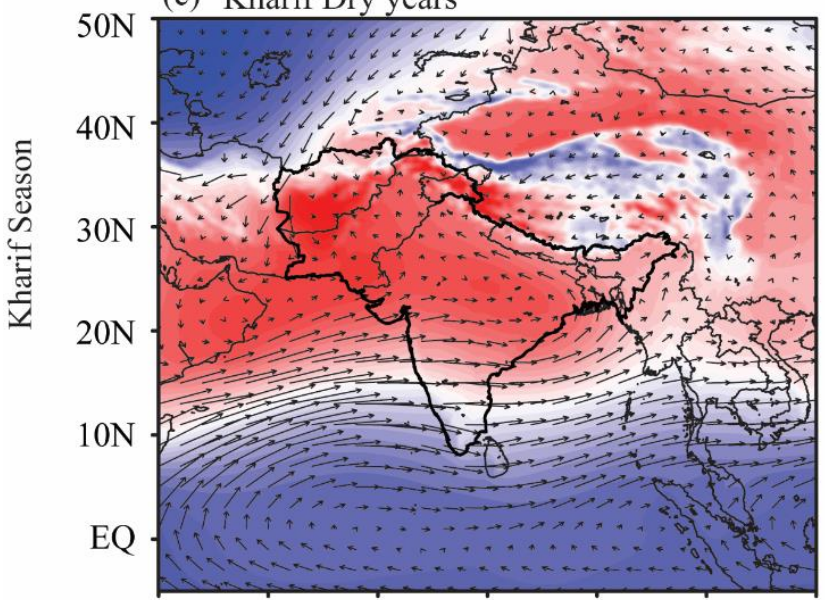

(e) Annual Dry years
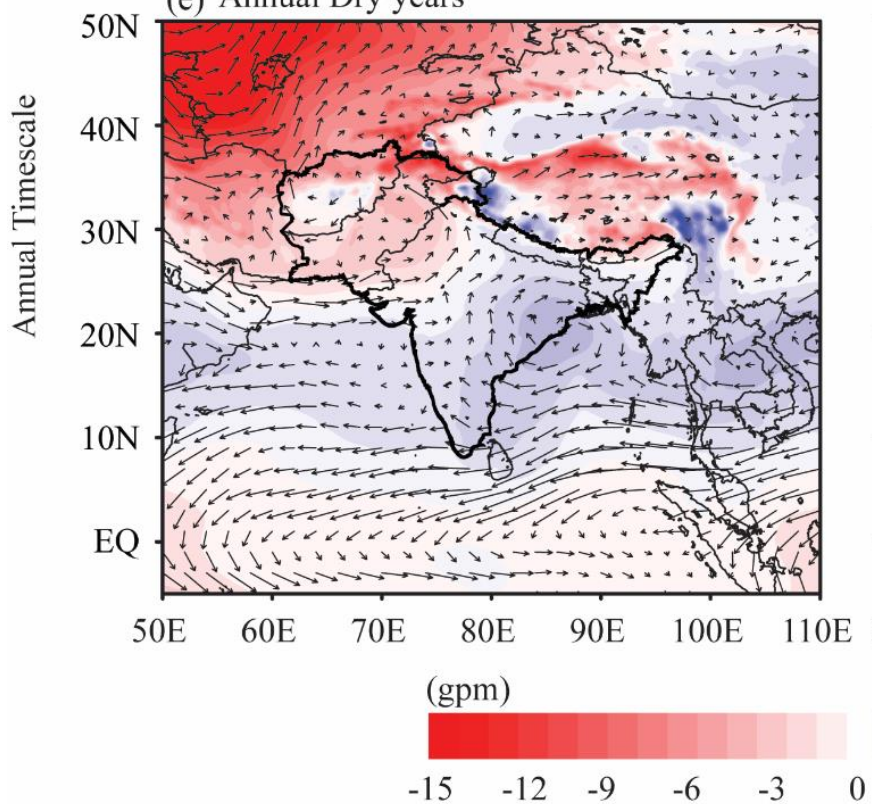

(b) Rabi Wet years

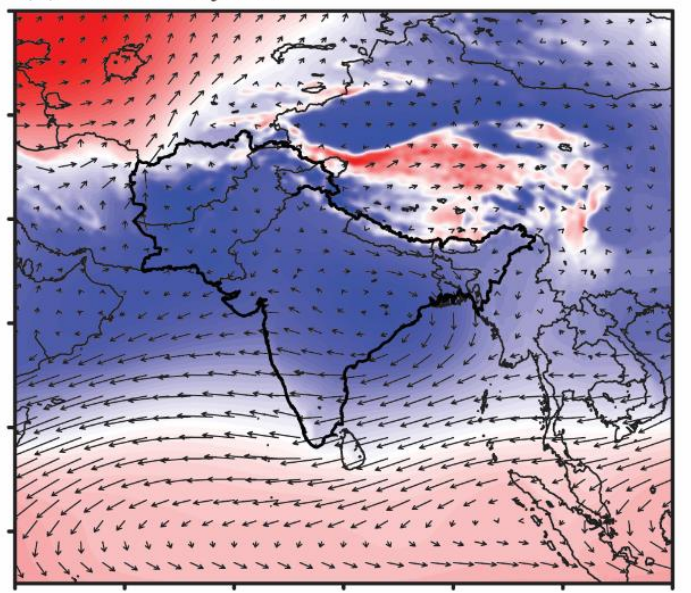

(d) Kharif Wet years

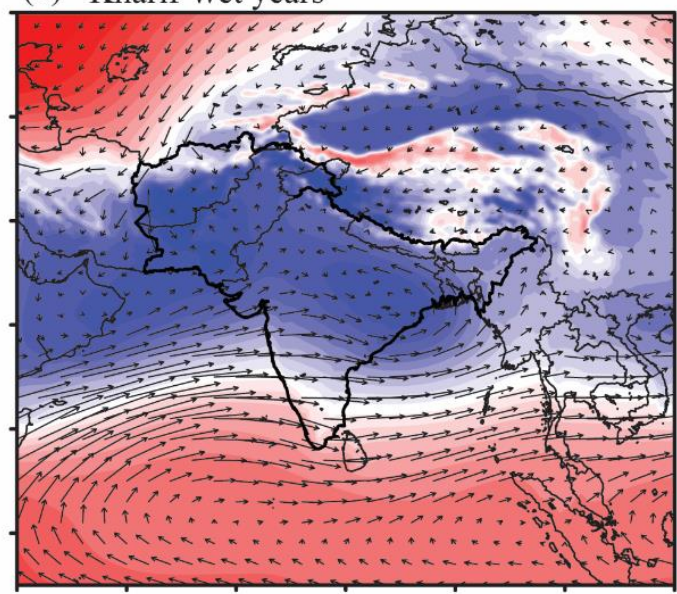

(f) Annual Wet years

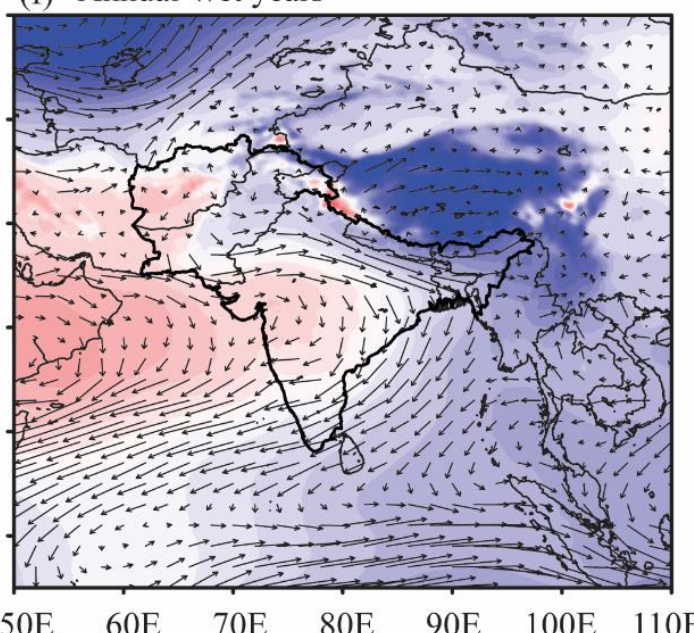

$\longrightarrow(10 \mathrm{~m} / \mathrm{s})$

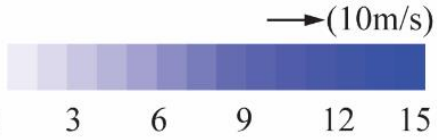

Fig. 6 Wind speed and geopotential height at $850 \mathrm{hPa}$ monthly anomaly for Rabi season,

Kharif season, and annual dry and wet years using ERA-5 datasets over SA including 
Pakistan during 1983-2019. The arrows indicate wind speed, and the shaded portion represents geopotential height.

(a) $2 \mathrm{~m}$ air temperature

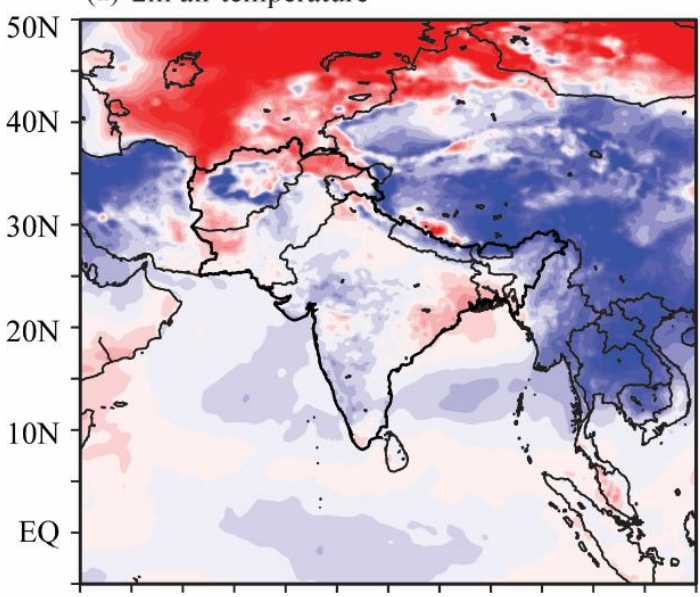

(c) Soil moisture

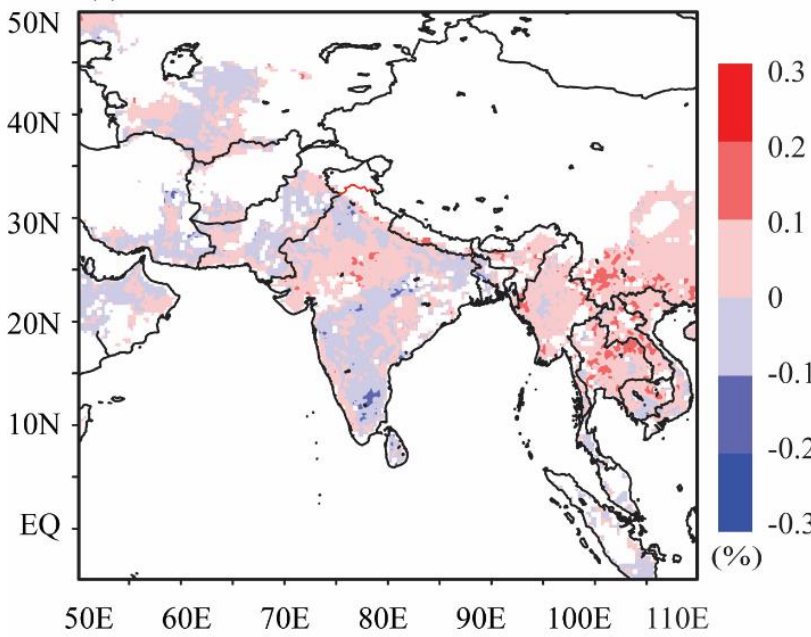

(b) Wind speed and geopotential height $850 \mathrm{hPa}$
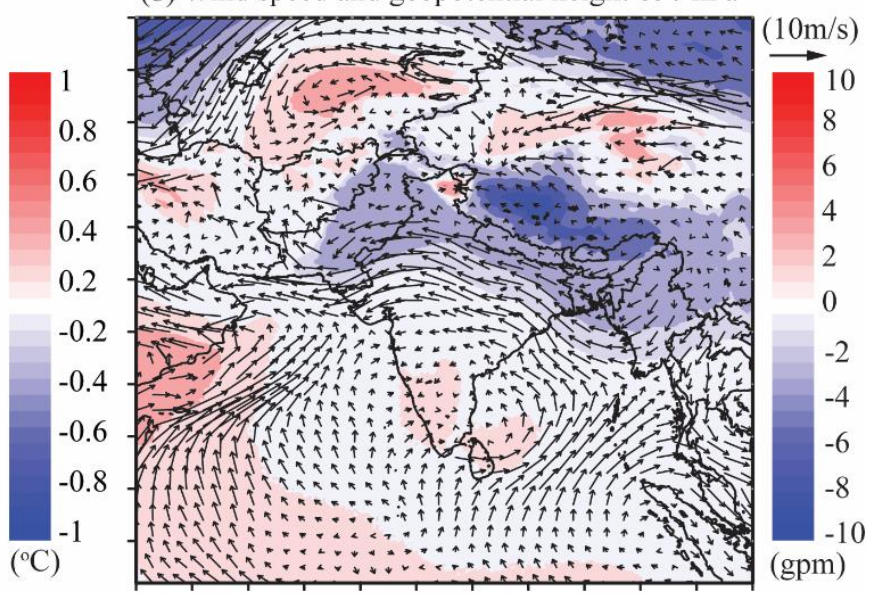

(d) Relative humidity $850 \mathrm{hPa}$

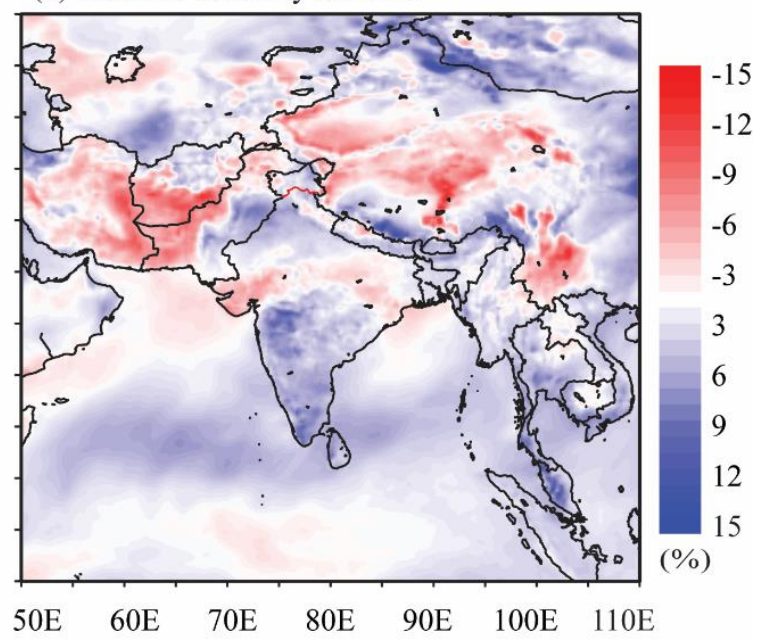

Fig. 7 Spatial distributions of differences over SA including Pakistan during 1983-2000 and 2001-2019 averaged anomalies for 2m air temperature (a), wind speed, and geopotential height at $850 \mathrm{hPa}$ (b), soil moisture (c), and relative humidity at $850 \mathrm{hPa}$ (d) using ERA-5 datasets. 
(a) Rabi Season

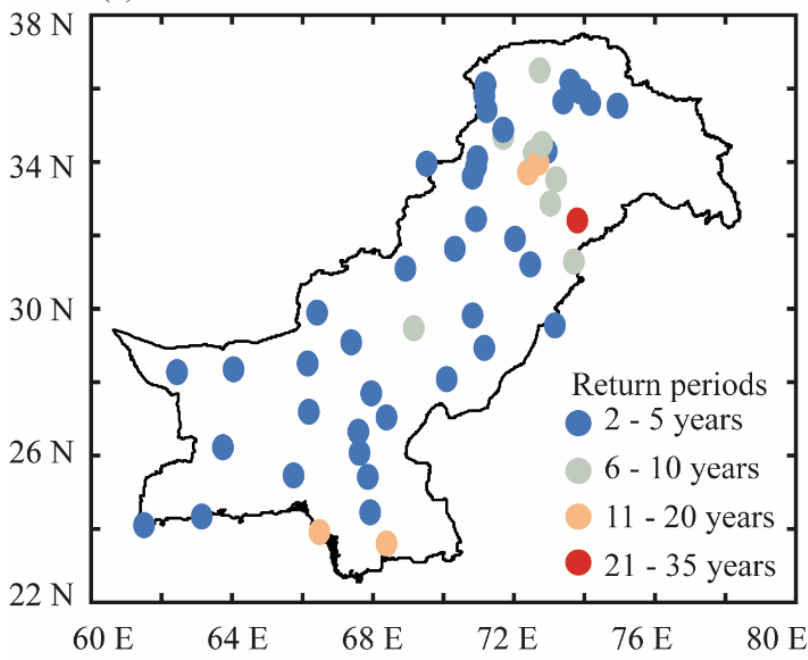

(b) Kharif Season

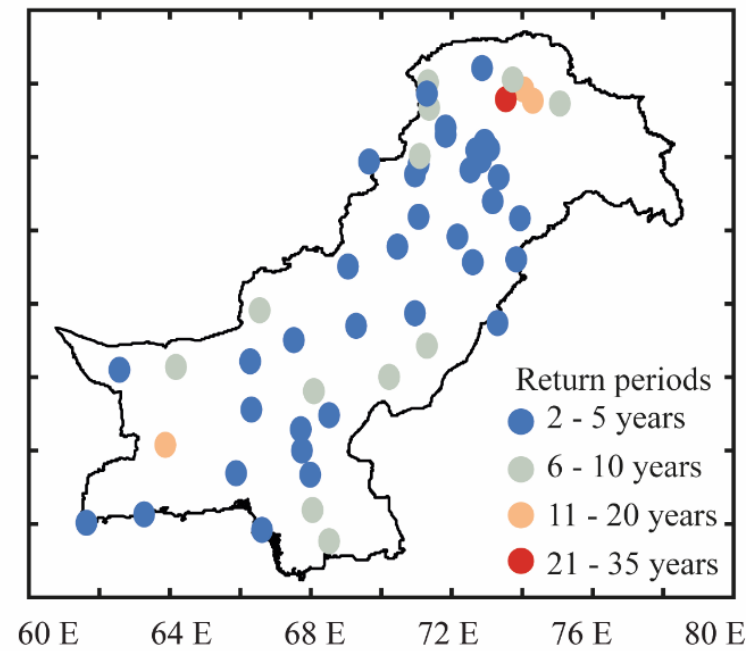

(c) Annual timescale

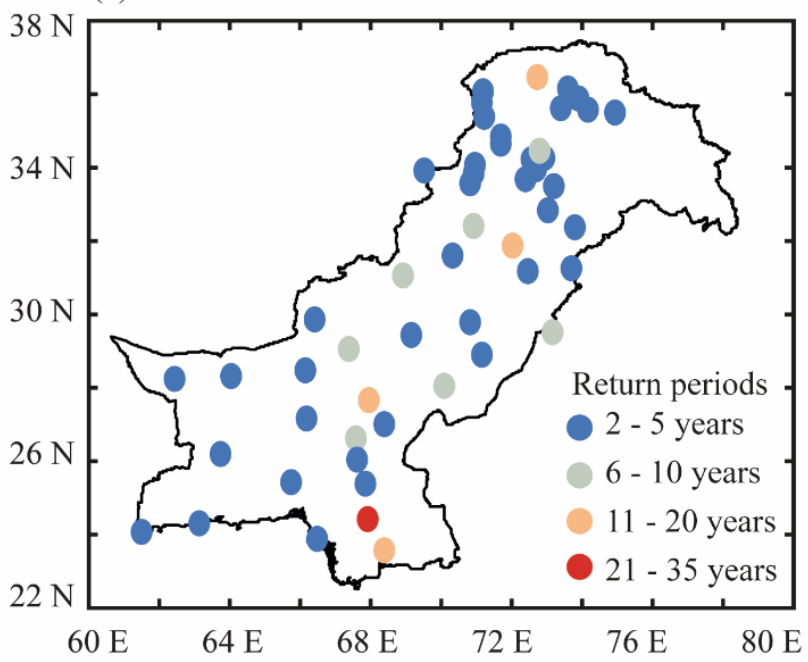

Fig. 8 Spatial distributions of changes of 35 years return period with a different degree of drought severity over 53 meteorological stations of Pakistan during the period of 1983 to 2019. The panel represents a) Rabi season, b) Kharif season, and c) annual timescale, respectively. 


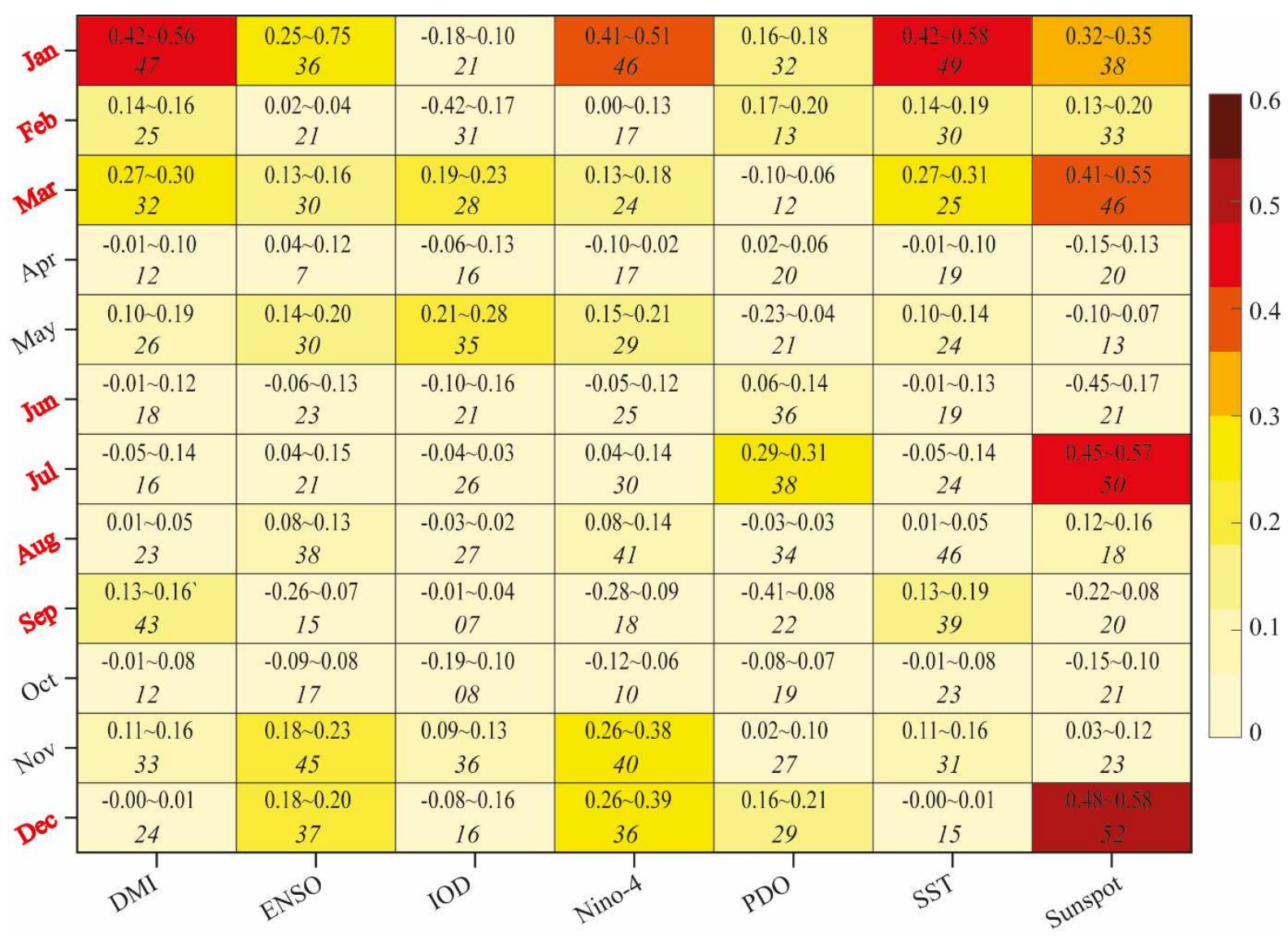

Climate Indices

Fig. 9 Pearson's correlation coefficients between monthly seasonal SPEI (Rabi and Kharif) and lagged large-scale climate indices based on 53 meteorological stations across the Pakistan growing season belt. In 12-month SPEI (December-March in target Rabi season and June-September in Kharif season) values of seven climate indices prior to the growing season were applied. In addition, the values with an italic number indicate meteorological stations which represent significant correlation $(p<0.05)$. The months labelled with red colours represent months of target year with respect to Rabi and Kharif seasons. 
(a) Rabi Season (SPEI-DMI)
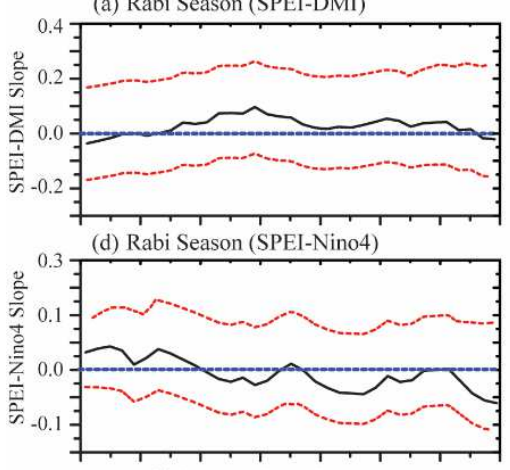

(g) Rabi Season (SPEI-Sunspot)
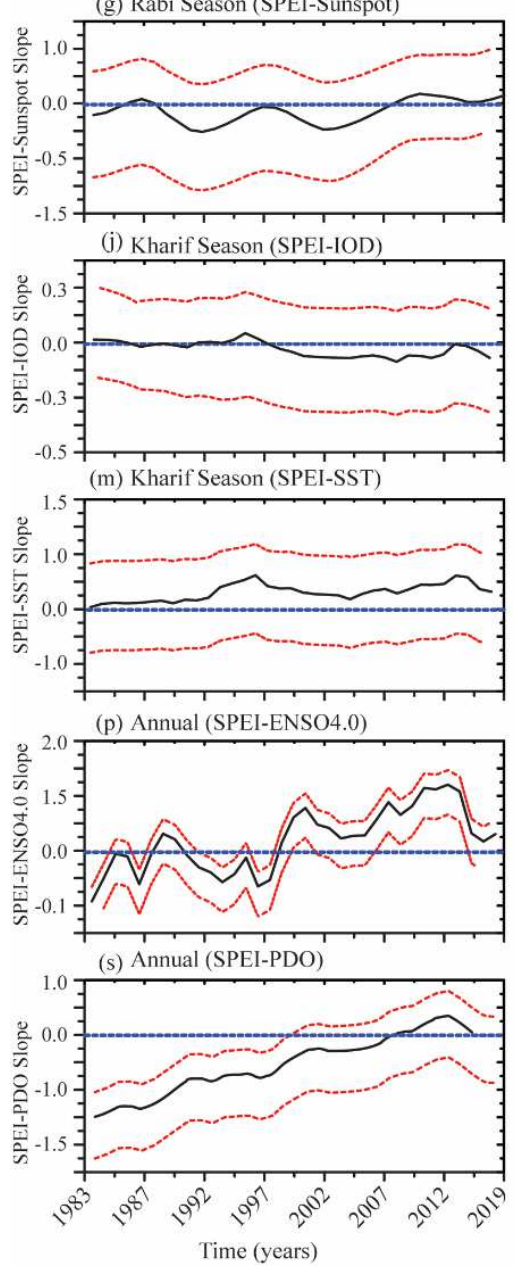

(b) Rabi Season (SPEI-ENSO4.0)

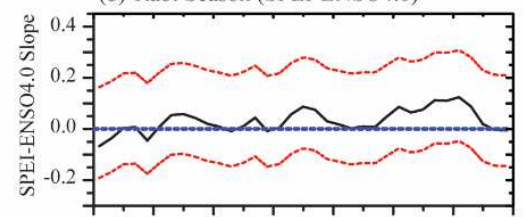

(e) Rabi Season (SPEI-PDO)
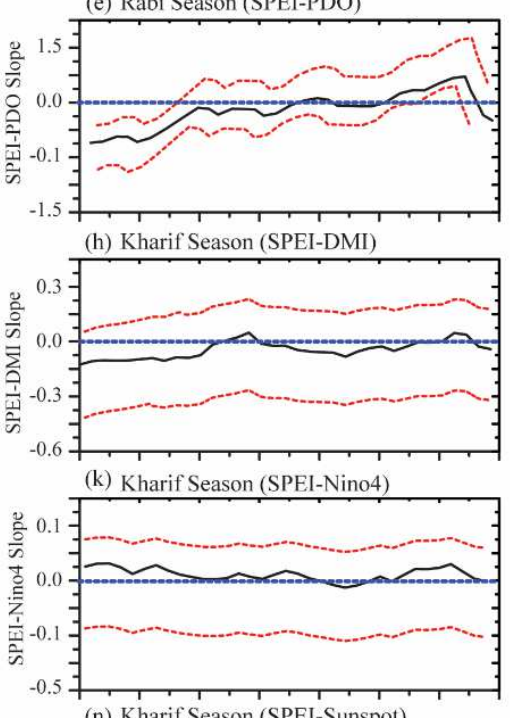

(n) Kharif Season (SPEI-Sunspot)
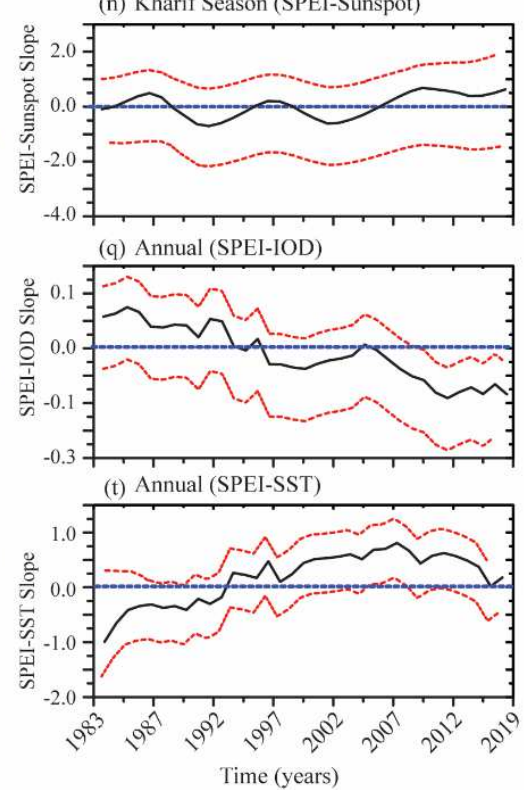

(c) Rabi Season (SPEI-IOD)
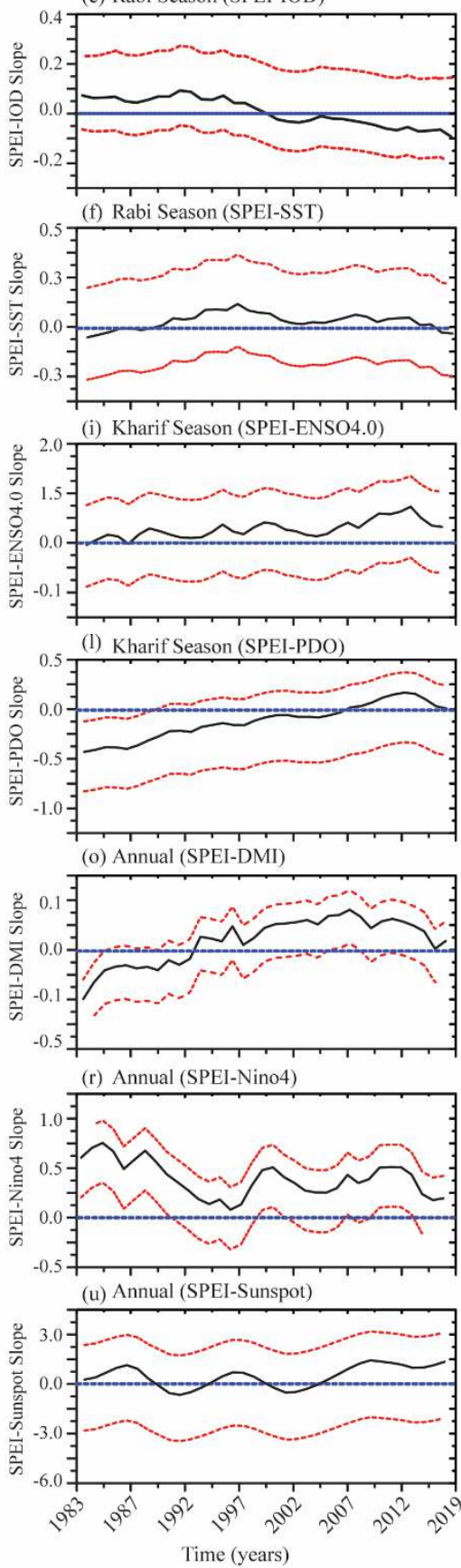

Fig. 10 Deviation in the relationship between regional SPEI (6-month) and seven large-scale climate indices fluctuations for Rabi season (a-g), Kharif season (h-n), and annual timescale (o-u) across Pakistan during 1983-2019, respectively. In panels, the solid black line indicates the appraised time-varying slopes, along with the 25 th and 75 th percentile credible interval lines (red dashed lines) using state-of-the-art Bayesian Dynamic Linear (BDL) model. 


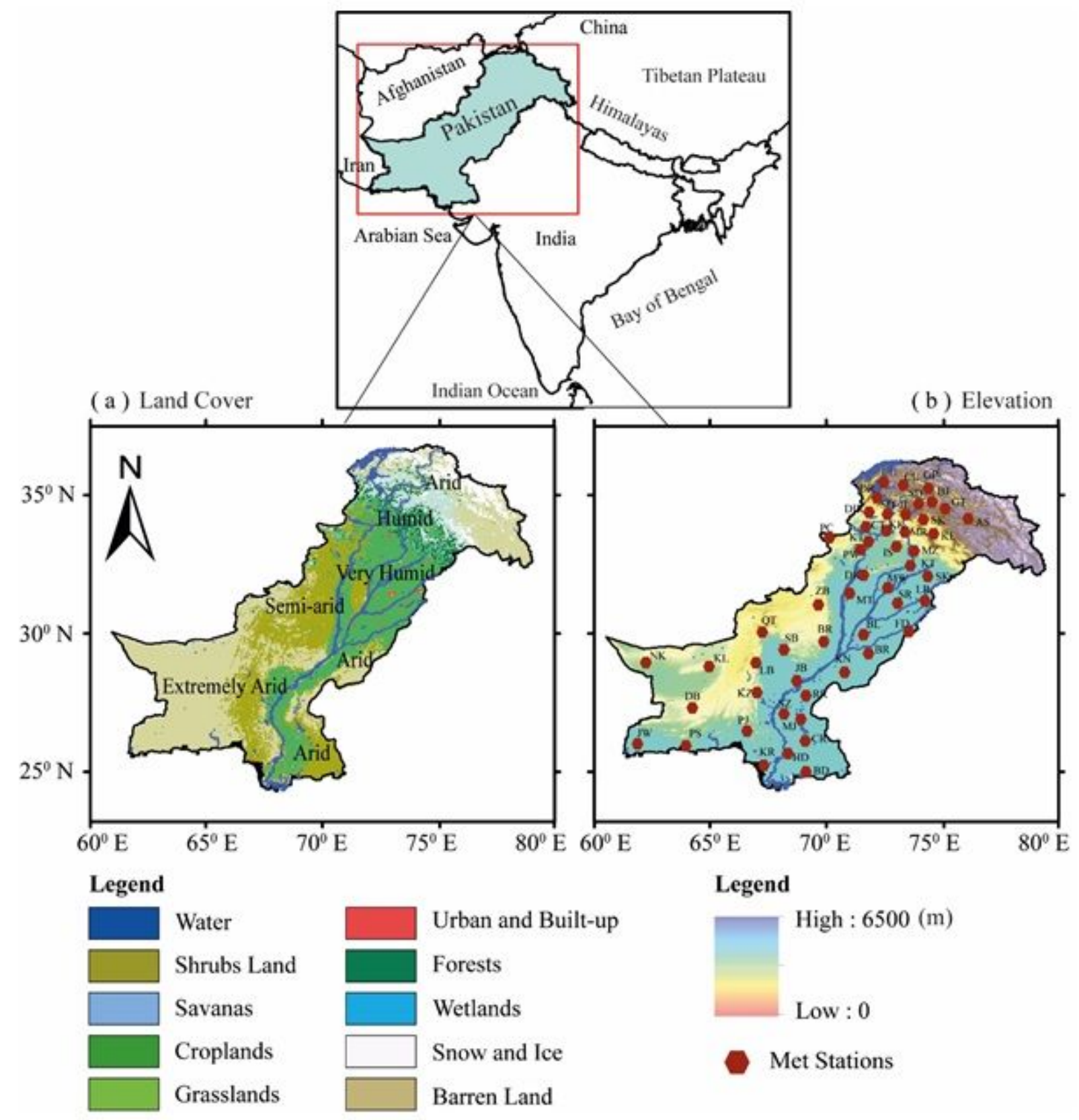

Figure 1

Location map of the Pakistan showing (a) land cover, aridity classes, and (b) elevation with 53 meteorological stations. Note: The designations employed and the presentation of the material on this map do not imply the expression of any opinion whatsoever on the part of Research Square concerning the legal status of any country, territory, city or area or of its authorities, or concerning the delimitation of its frontiers or boundaries. This map has been provided by the authors. 
(a) Rabi Season

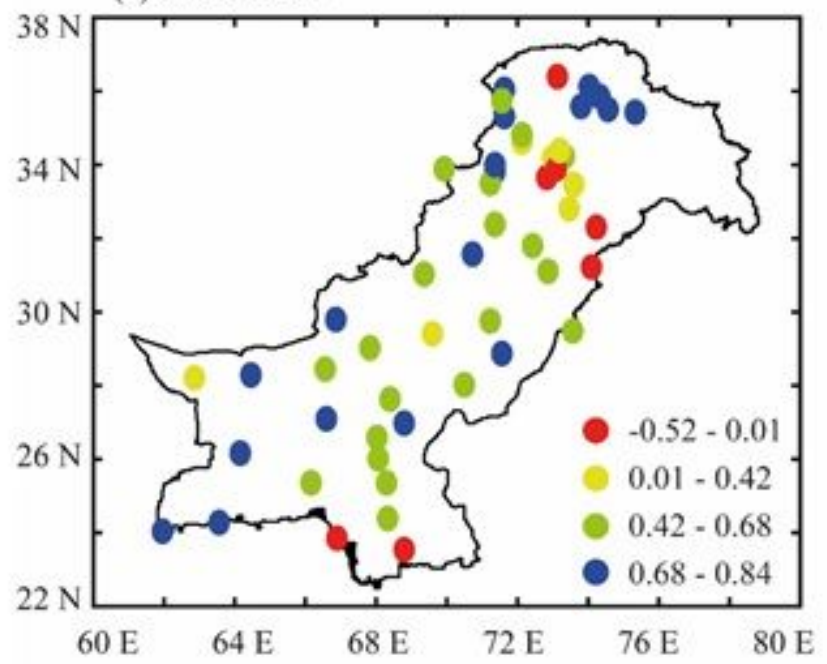

(c) Annual timescale

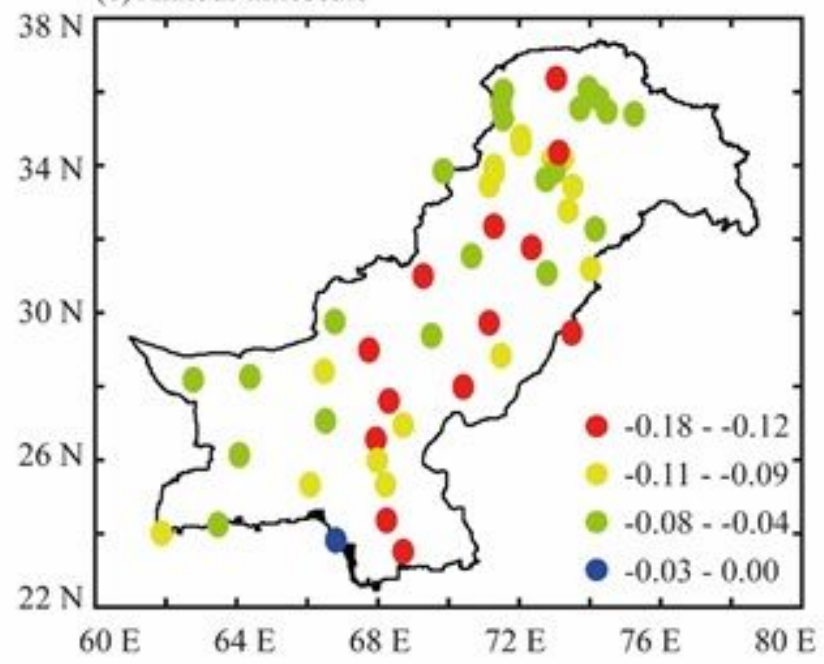

b) Kharif Season

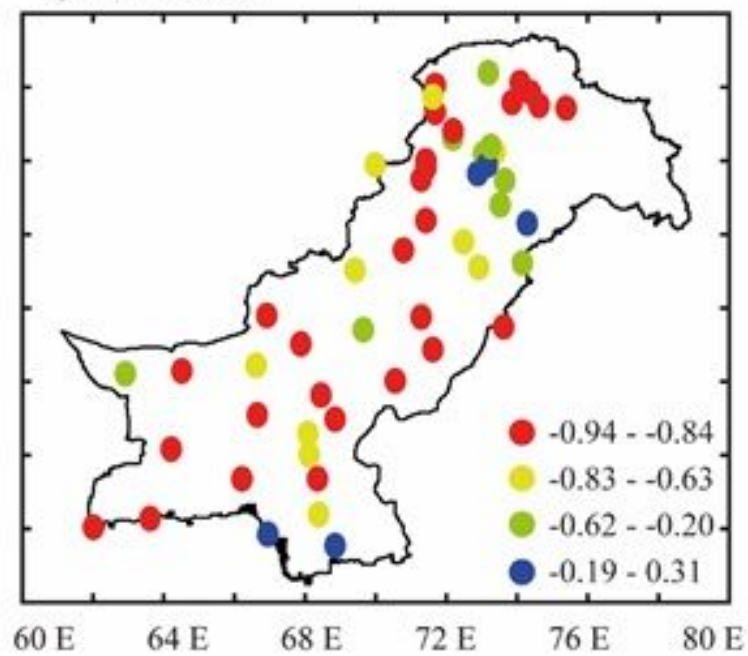

$60 \mathrm{E}$

$0 \mathrm{E}$

\section{.}


(a) Rabi SPEI Trends

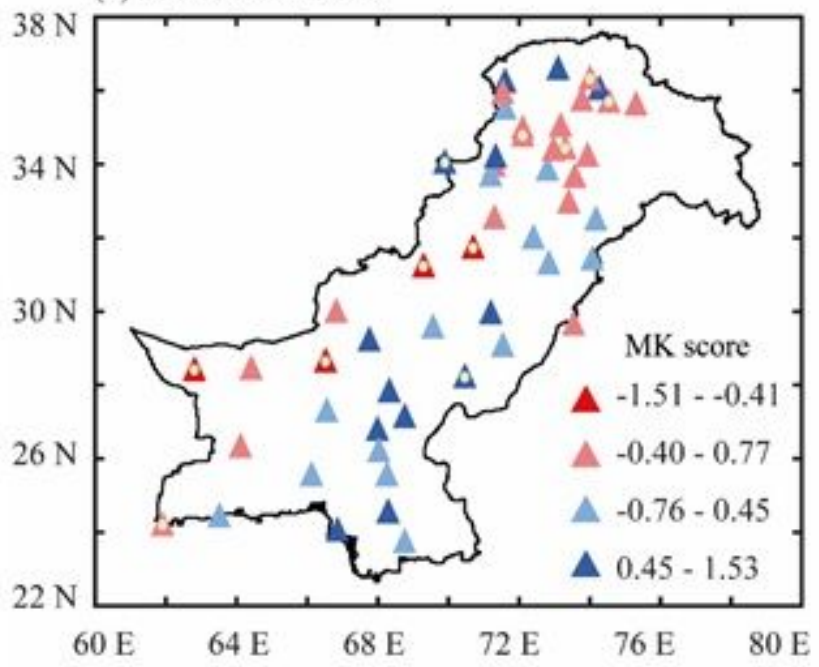

(c) Annual SPEI Trends (b) Kharif SPEI Trends
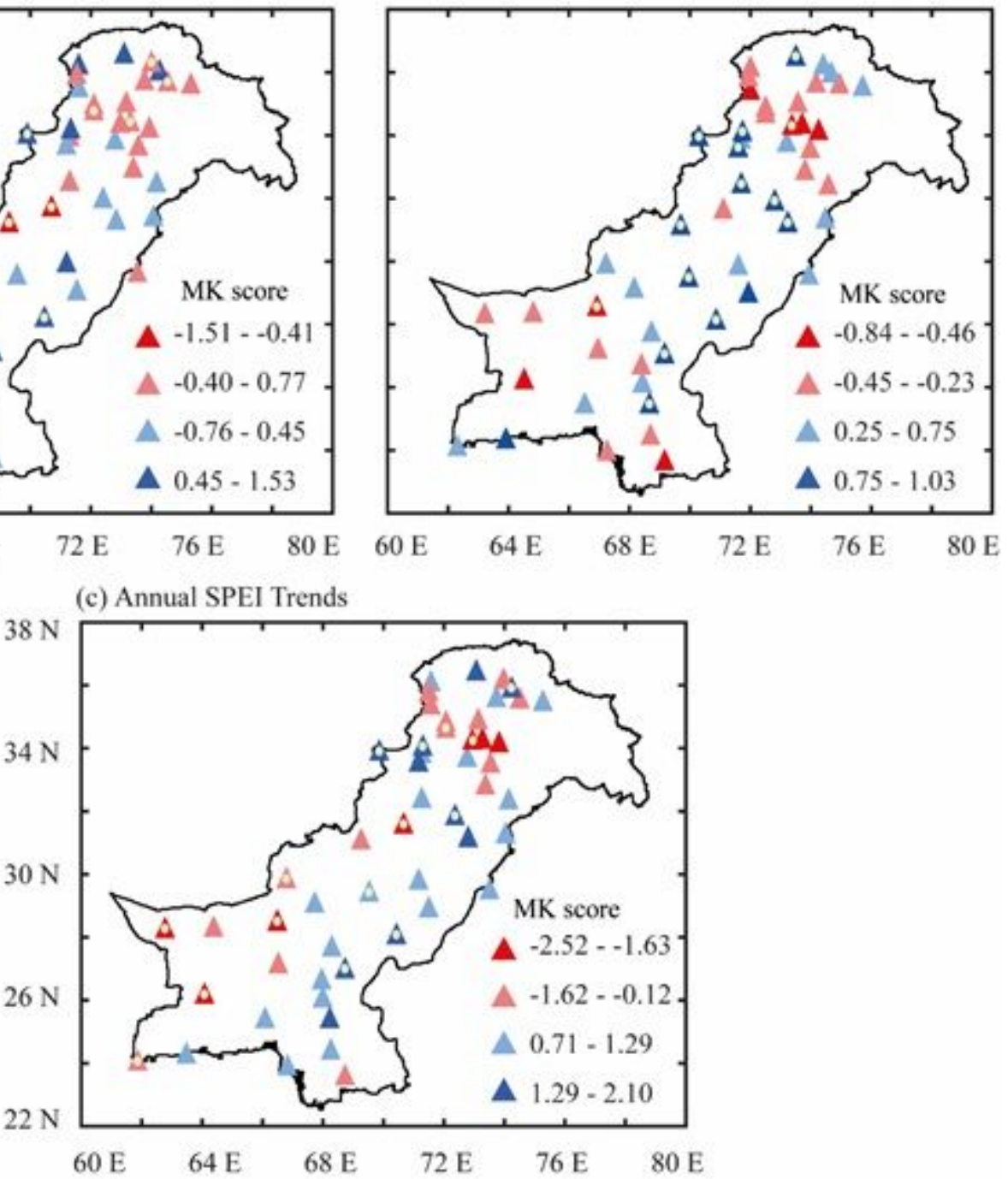

Figure 3

Spatial distribution of monthly SPEl trends during 1983-2019; a) Rabi season, b) Kharif season, and c) Annual. The light-yellow dots represent the stations where modified-MK test passed the significance test at $95 \%$ confidence. 
(a) Rabi Season

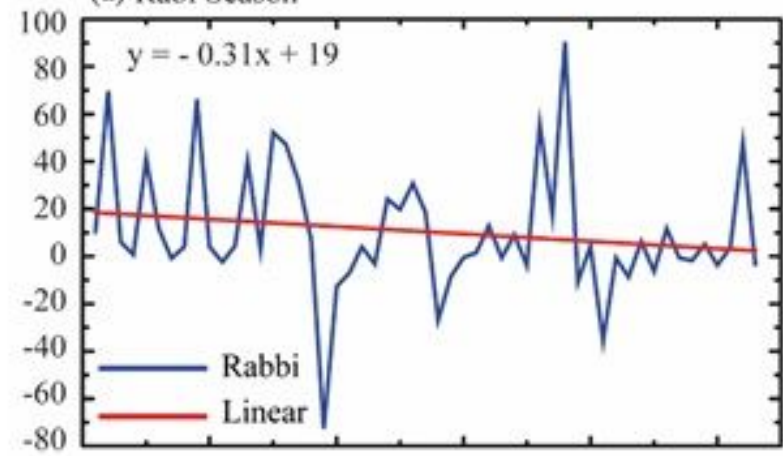

(c) Annual timescale

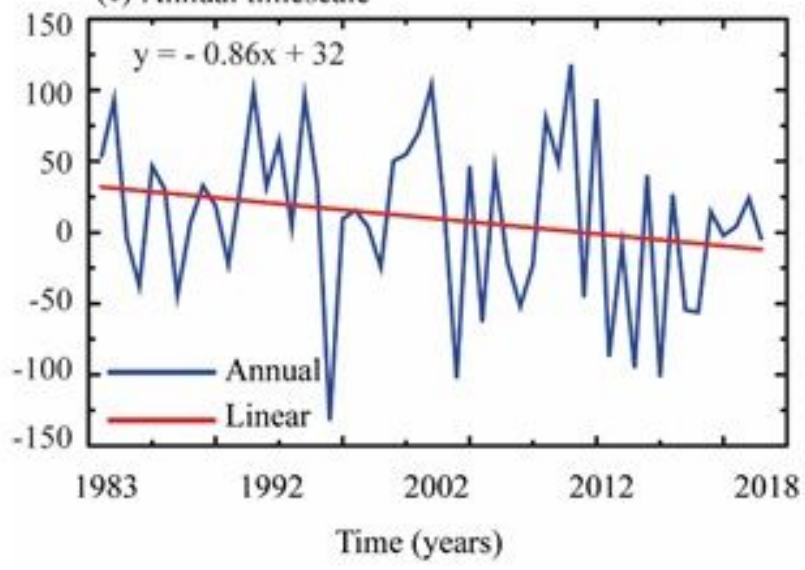

(b) Kharif Season

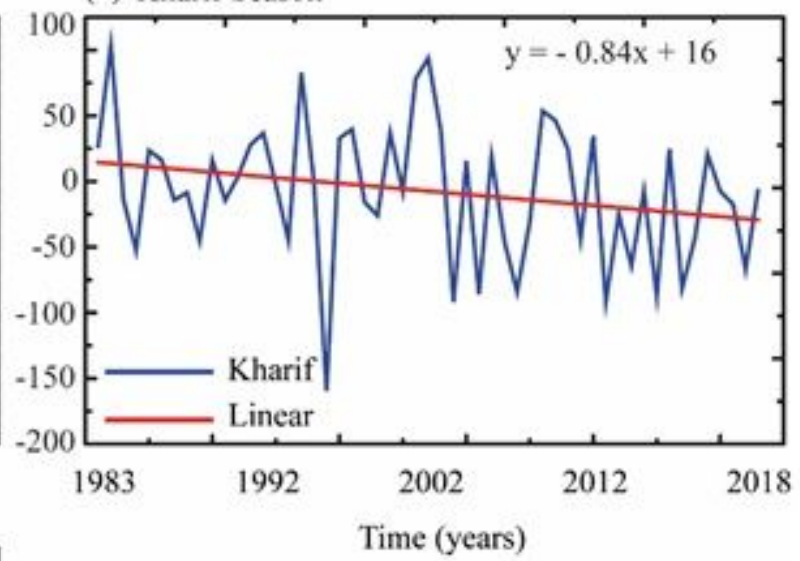

\section{Figure 4}

Linear regression-based trend of annual SPEI during 1983-2019; a) Rabi season, b) Kharif season, and c) annual timescale, respectively. The red line indicates the regression best fit line, and the equation shows the magnitude of the slope. 
(a) Rabi Season

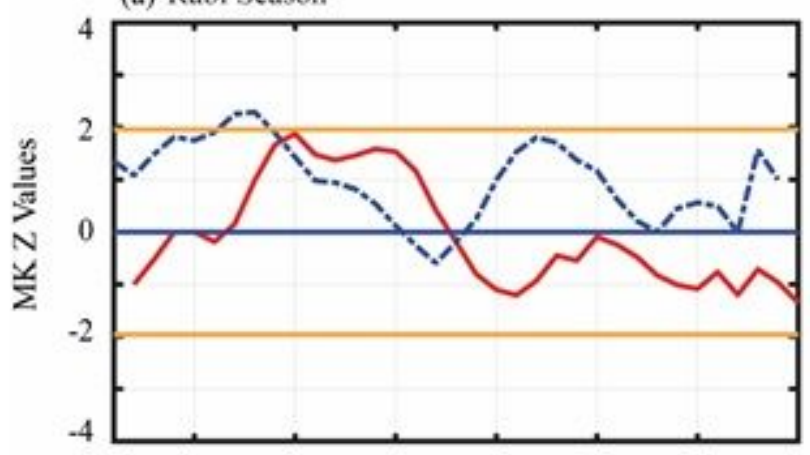

(c) Annual timescale

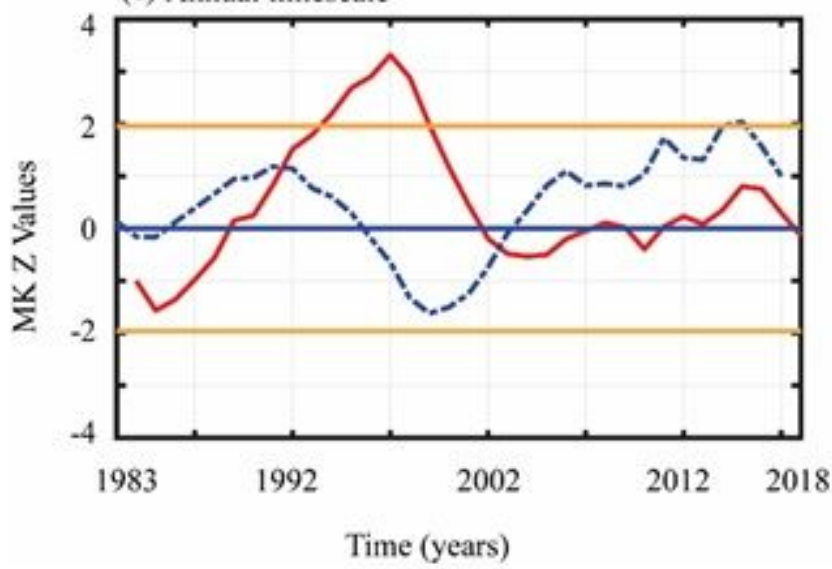

(b) Kharif Season

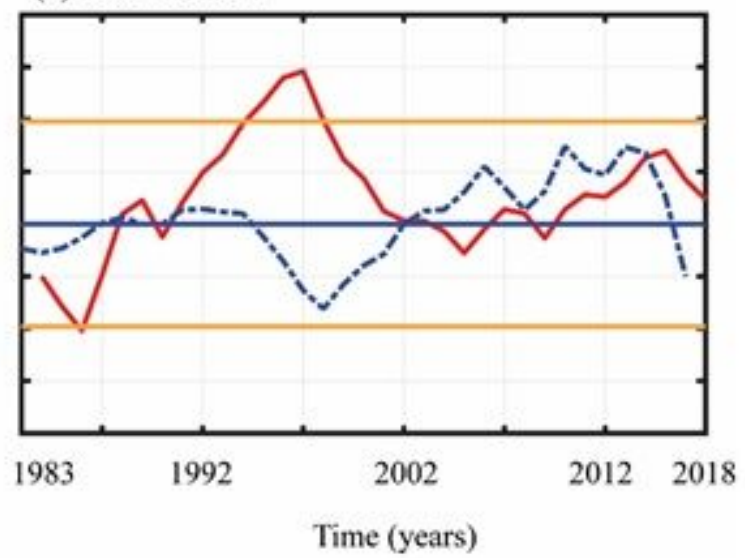

Progressive Series

Retrograde Series

Significance Level

\section{Figure 5}

SQMK trend of annual mean SPEI during 1983-2019; a) Rabi season, b) Kharif season, and c) annual timescale, respectively. 
(a) Rabi Dry years

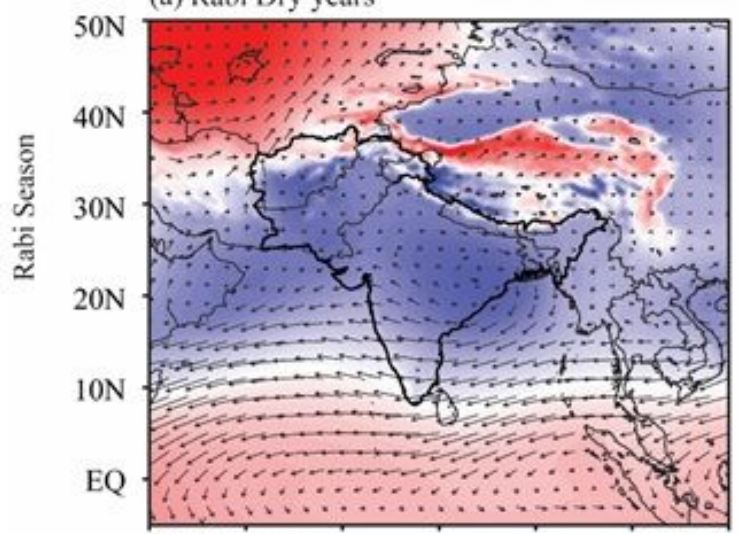

(c) Kharif Dry years

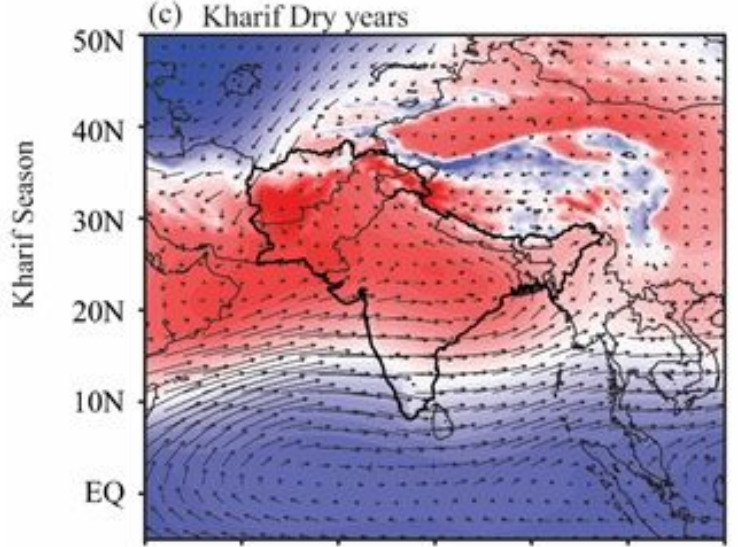

(e) Annual Dry years

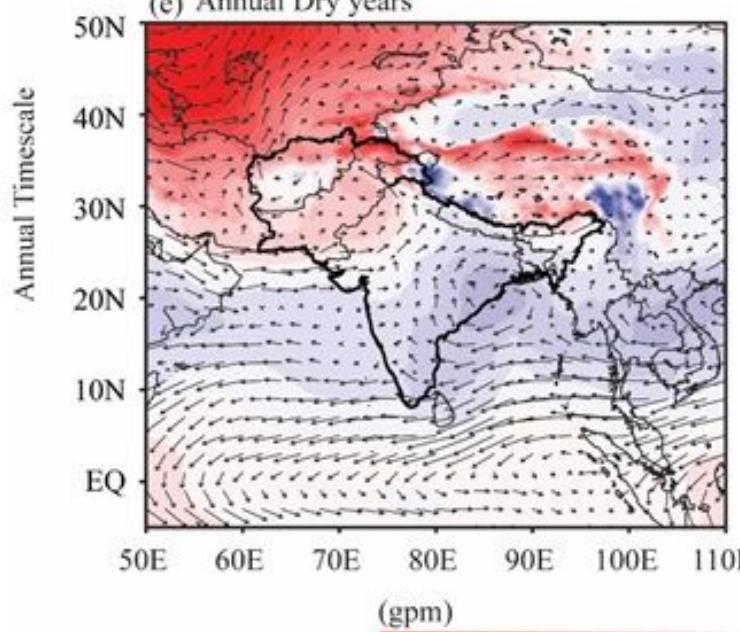

(gpm) (b) Rabi Wet years

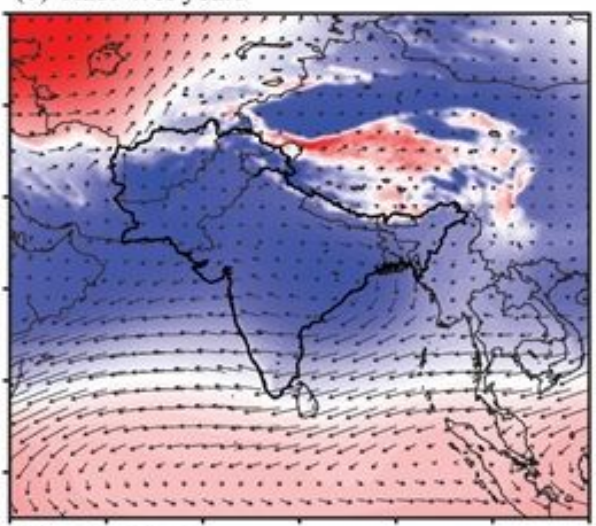

(d) Kharif Wet years

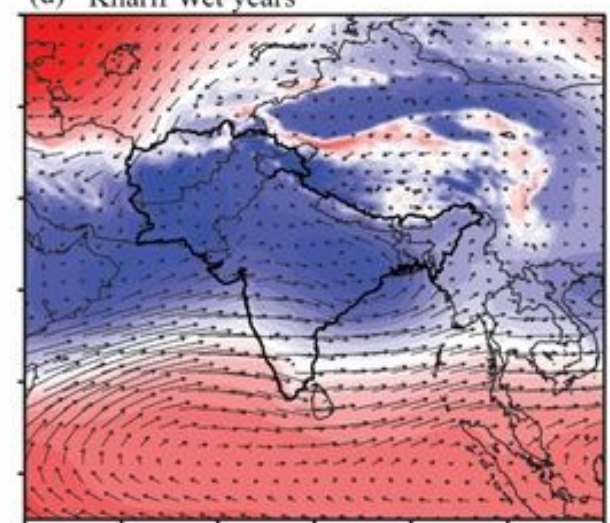

(f) Annual Wet years

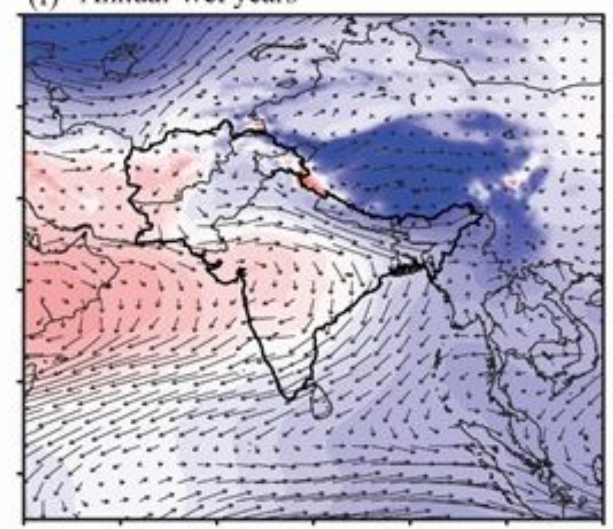

$\begin{array}{lllllll}50 \mathrm{E} & 60 \mathrm{E} & 70 \mathrm{E} & 80 \mathrm{E} & 90 \mathrm{E} & 100 \mathrm{E} & 110 \mathrm{E}\end{array}$

$\begin{array}{lllllllllll}-15 & -12 & -9 & -6 & -3 & 0 & 3 & 6 & 9 & 12 & 15\end{array}$

\section{Figure 6}

Wind speed and geopotential height at $850 \mathrm{hPa}$ monthly anomaly for Rabi season, Kharif season, and annual dry and wet years using ERA-5 datasets over SA including Pakistan during 1983-2019. The arrows indicate wind speed, and the shaded portion represents geopotential height. Note: The designations employed and the presentation of the material on this map do not imply the expression of any opinion whatsoever on the part of Research Square concerning the legal status of any country, territory, city or 
area or of its authorities, or concerning the delimitation of its frontiers or boundaries. This map has been provided by the authors.

(a) $2 \mathrm{~m}$ air temperature

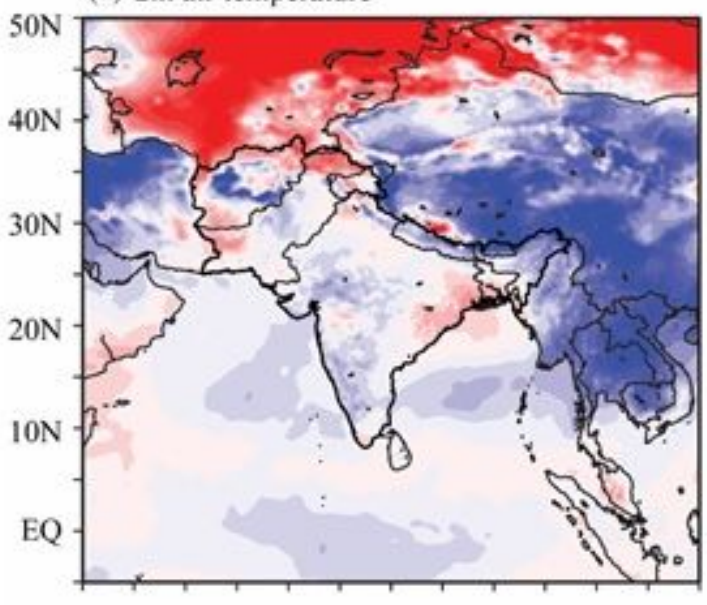

(c) Soil moisture

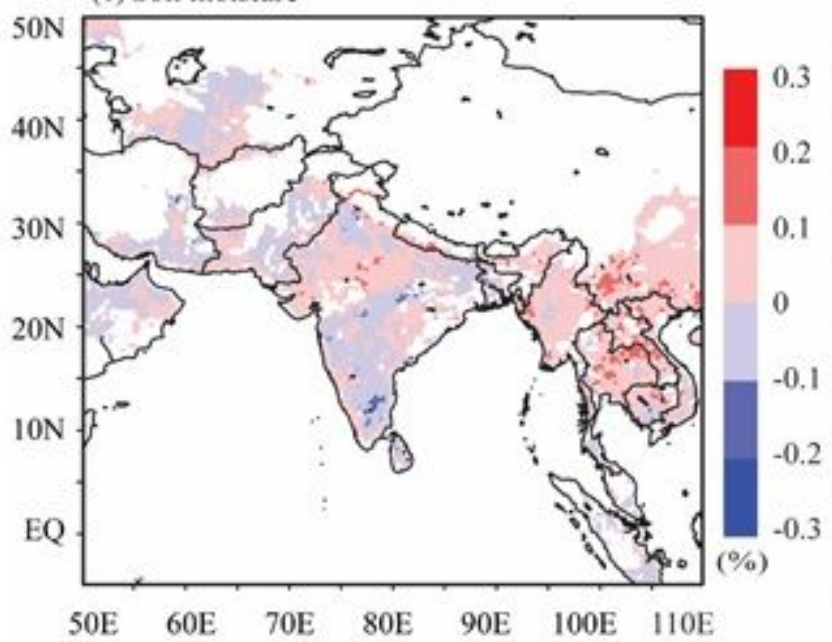

(b) Wind speed and geopotential height $850 \mathrm{hPa}$

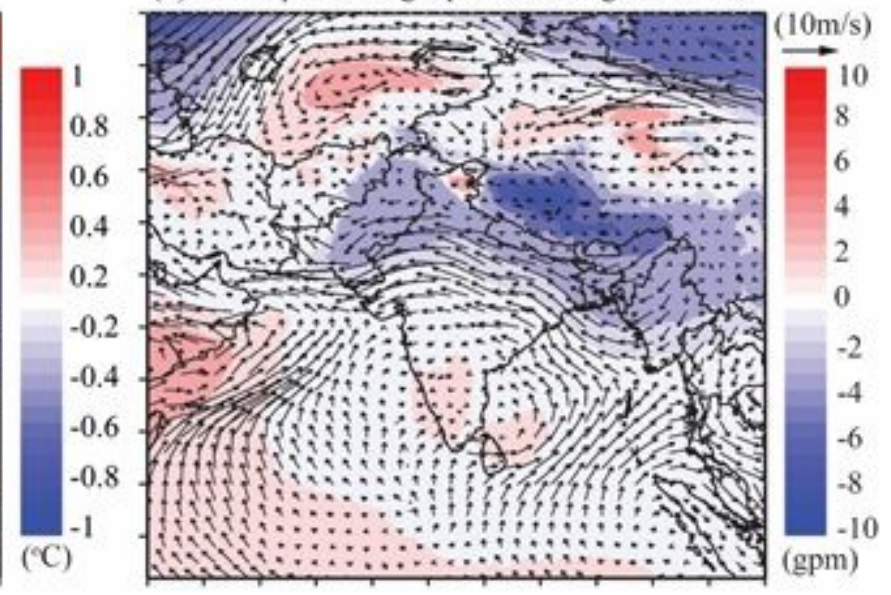

(d) Relative humidity $850 \mathrm{hPa}$

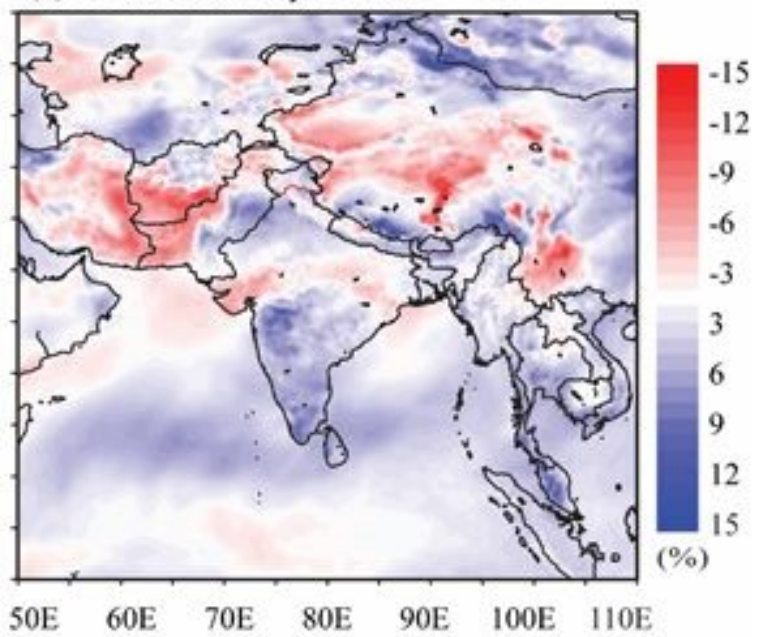

\section{Figure 7}

Spatial distributions of differences over SA including Pakistan during 1983-2000 and 2001-2019 averaged anomalies for $2 \mathrm{~m}$ air temperature (a), wind speed, and geopotential height at $850 \mathrm{hPa}(\mathrm{b})$, soil moisture (c), and relative humidity at $850 \mathrm{hPa}$ (d) using ERA-5 datasets. Note: The designations employed and the presentation of the material on this map do not imply the expression of any opinion whatsoever on the part of Research Square concerning the legal status of any country, territory, city or area or of its authorities, or concerning the delimitation of its frontiers or boundaries. This map has been provided by the authors. 
(a) Rabi Season

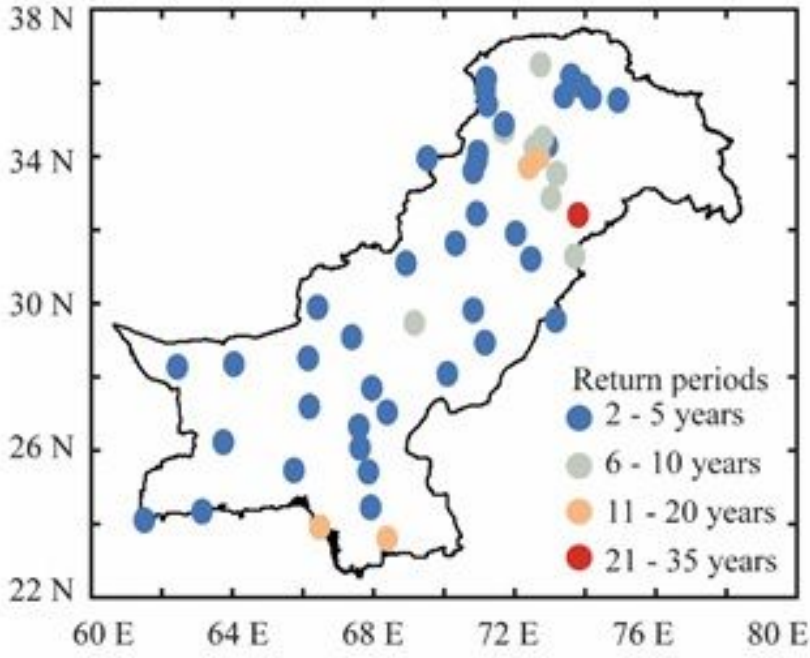

(c) Annual timescale (b) Kharif Season

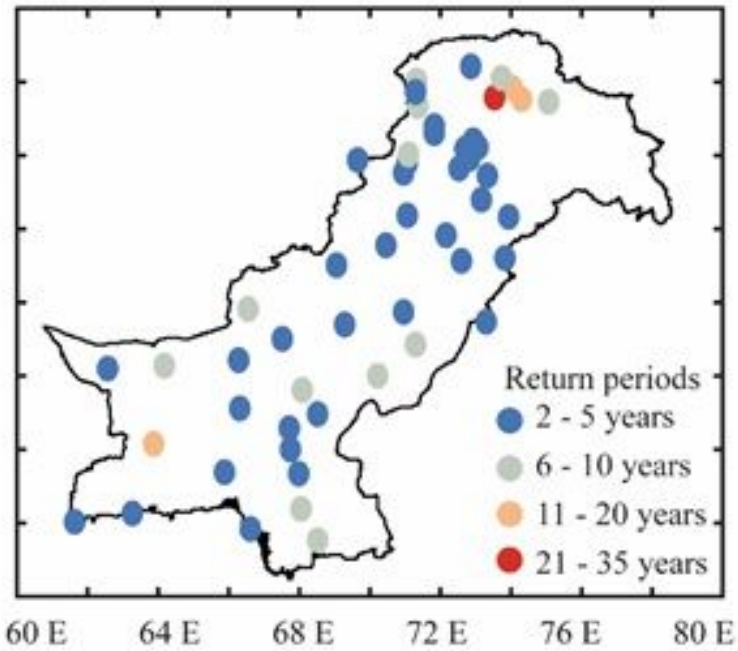

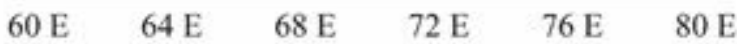

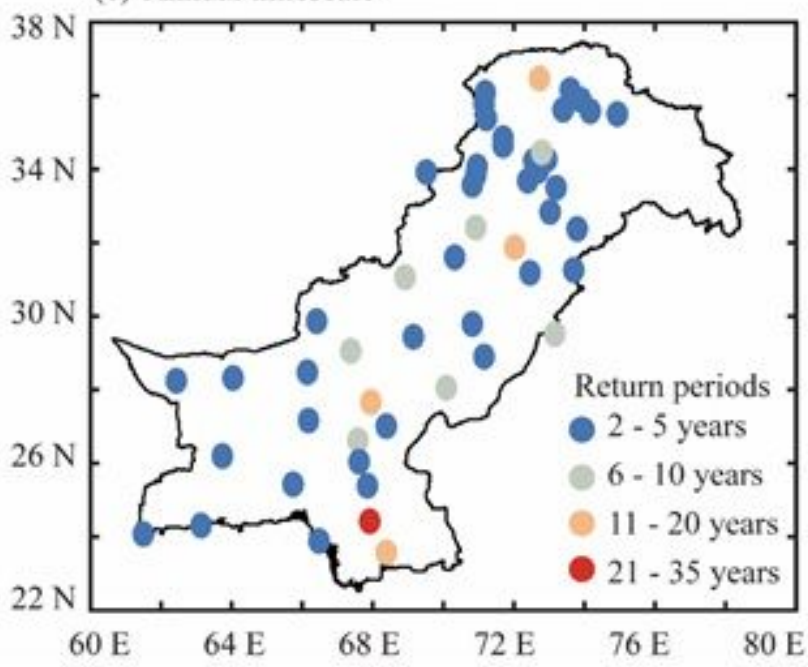

Figure 8

Spatial distributions of changes of 35 years return period with a different degree of drought severity over 53 meteorological stations of Pakistan during the period of 1983 to 2019. The panel represents a) Rabi season, b) Kharif season, and c) annual timescale, respectively. 


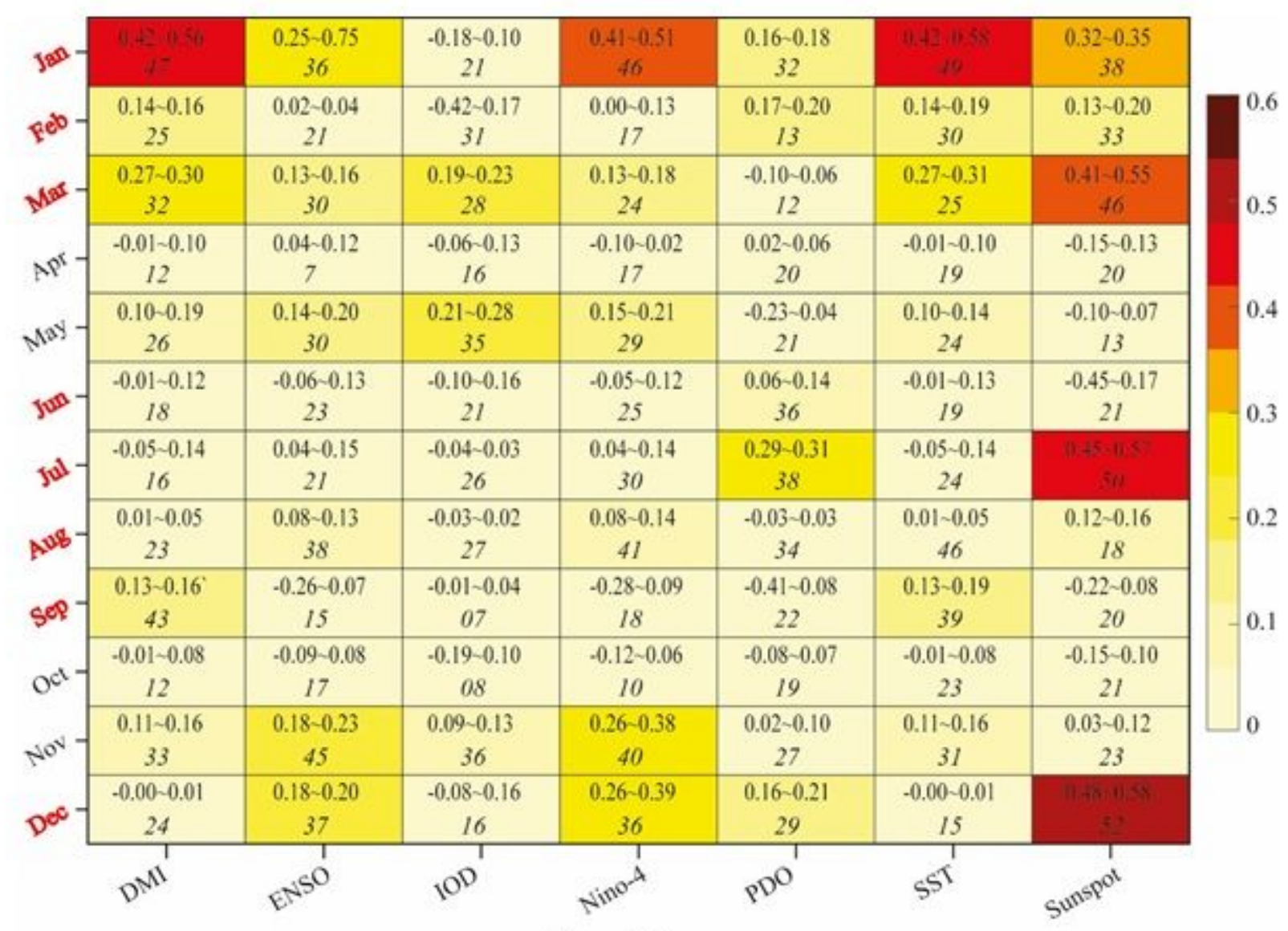

Climate Indices

Figure 9

Pearson's correlation coefficients between monthly seasonal SPEI (Rabi and Kharif) and lagged largescale climate indices based on 53 meteorological stations across the Pakistan growing season belt. In 12-month SPEI (December-March in target Rabi season and June-September in Kharif season) values of seven climate indices prior to the growing season were applied. In addition, the values with an italic number indicate meteorological stations which represent significant correlation $(p<0.05)$. The months labelled with red colours represent months of target year with respect to Rabi and Kharif seasons. 
(a) Rabi Season (SPEI-DMI)

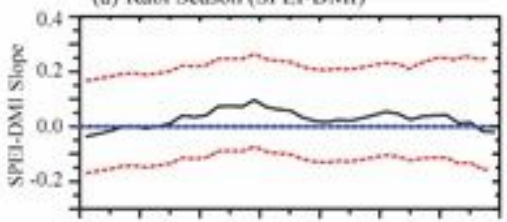

(d) Rabi Season (SPEI-Nino4)

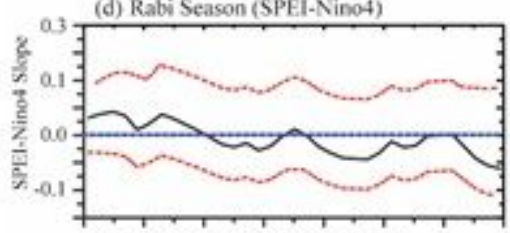

(g) Rabi Season (SPEI-Sunspot)

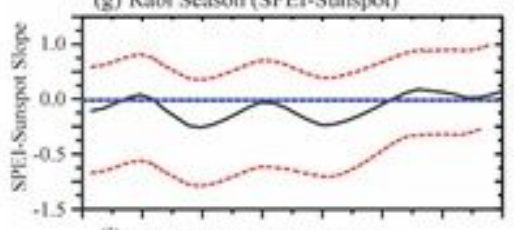

(j) Kharif Season (SPEI-IOD)

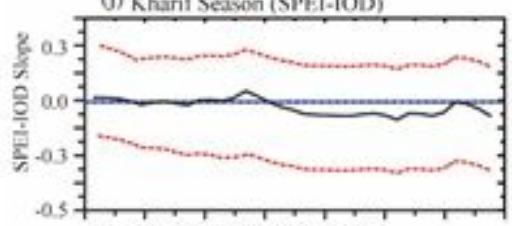

(m) Kharir Season (SPEI-SST)

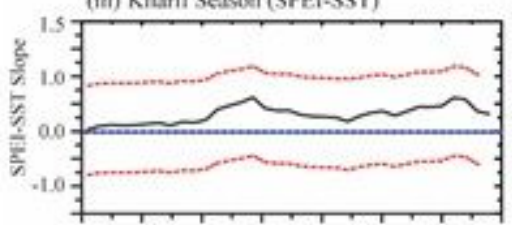

(p) Anneal (SPEI-ENSO4,0)
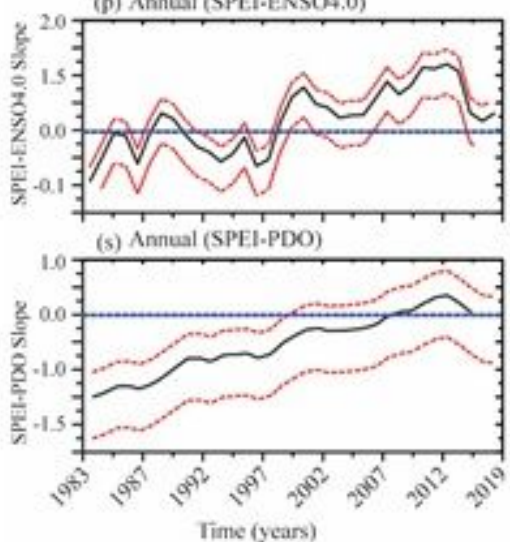

(b) Rabi Season (SPEI-ENSO4,0)

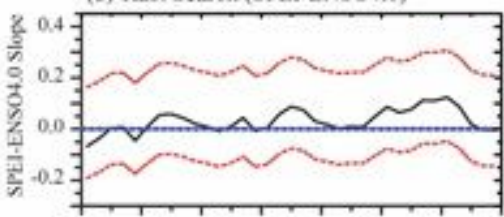

(e) Rabi Season (SPEI-PDO)

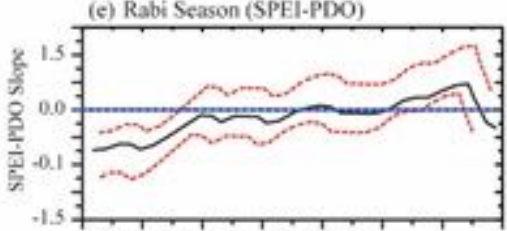

(h) Kharif Season (SPEI-DMI)

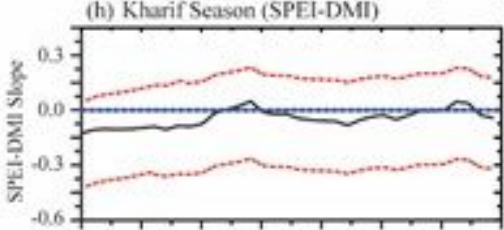

(k) Kharif Season (SPEI-Nino4)

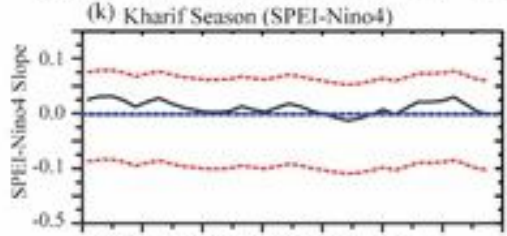

(n) Kharif Season (SPEl-Sunspot)

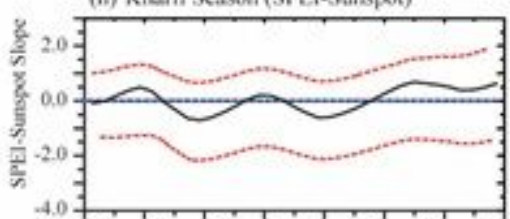

(q) Anneal (SPEI-IOD)

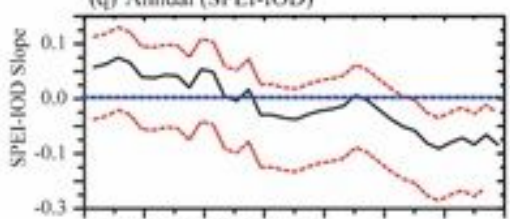

(t) Annual (SPEI-SST)

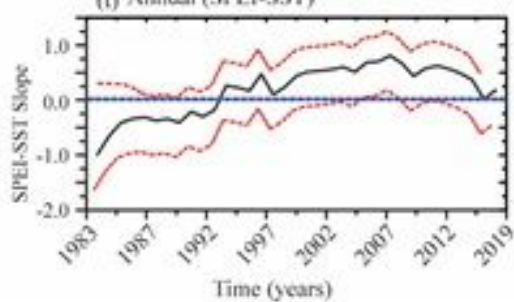

(c) Rabi Scason (SPEL-IOD)
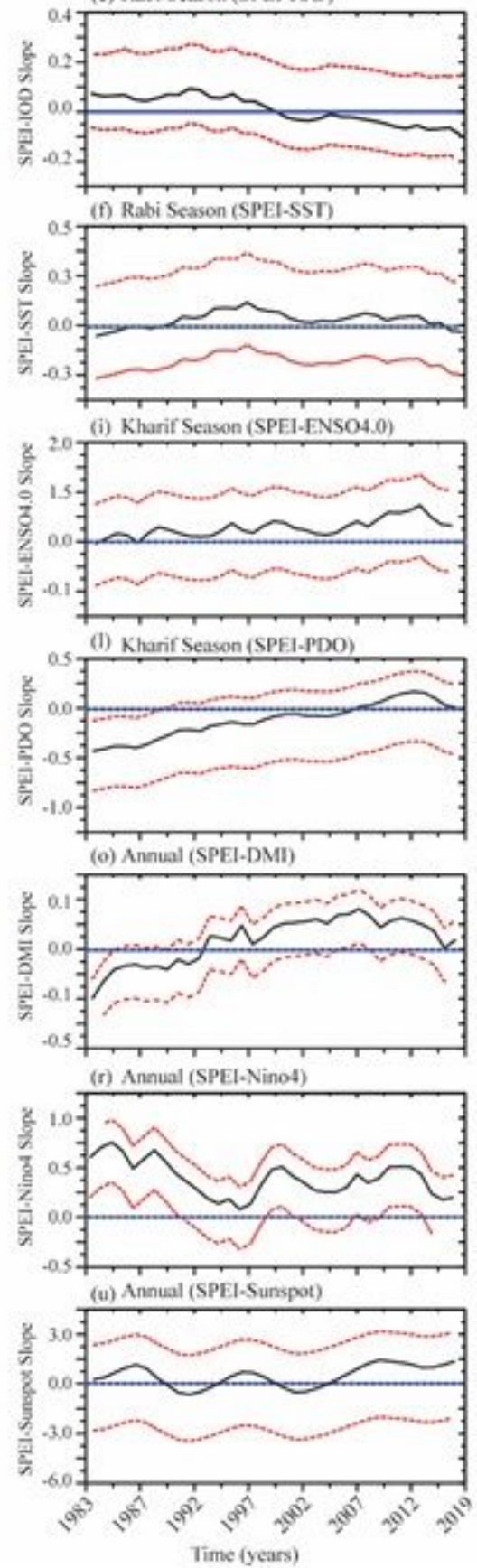

\section{Figure 10}

Deviation in the relationship between regional SPEI (6-month) and seven large-scale climate indices fluctuations for Rabi season (a-g), Kharif season (h-n), and annual timescale (o-u) across Pakistan during 1983-2019, respectively. In panels, the solid black line indicates the appraised time-varying slopes, along with the 25th and 75th percentile credible interval lines (red dashed lines) using state-of-the-art Bayesian Dynamic Linear (BDL) model. 


\section{Supplementary Files}

This is a list of supplementary files associated with this preprint. Click to download.

- Supplymentrymaterial.docx 